\title{
From Discrete Gravity Survey Data to a High-resolution Gravity Field Representation in the Nordic-Baltic Region
}

Märdla, Silja; Ågren, Jonas; Strykowski, Gabriel; Oja, Tõnis; Ellmann, Artu; Forsberg, René; BilkerKoivula, Mirjam; Omang, Ove; Paršelinas, Eimuntas; Liepinš, Ivars

Total number of authors:

11

Published in:

Marine Geodesy

Link to article, DOI:

$10.1080 / 01490419.2017 .1326428$

Publication date:

2017

Document Version

Peer reviewed version

Link back to DTU Orbit

Citation (APA):

Märdla, S., Agren, J., Strykowski, G., Oja, T., Ellmann, A., Forsberg, R., Bilker-Koivula, M., Omang, O., Paršelinas, E., Liepinš, I., \& Kaminskis, J. (2017). From Discrete Gravity Survey Data to a High-resolution Gravity Field Representation in the Nordic-Baltic Region. Marine Geodesy, 40(6), 416-453.

https://doi.org/10.1080/01490419.2017.1326428

\section{General rights}

Copyright and moral rights for the publications made accessible in the public portal are retained by the authors and/or other copyright owners and it is a condition of accessing publications that users recognise and abide by the legal requirements associated with these rights.

- Users may download and print one copy of any publication from the public portal for the purpose of private study or research.

- You may not further distribute the material or use it for any profit-making activity or commercial gain

- You may freely distribute the URL identifying the publication in the public portal 


\section{From discrete gravity survey data to a high- resolution gravity field representation in the Nordic-Baltic region}

Silja Märdla, Jonas Ågren, Gabriel Strykowski, Tõnis Oja, Artu Ellmann, René Forsberg, Mirjam Bilker-Koivula, Ove Omang, Eimuntas Paršeliūnas, Ivars Liepinš \& Jānis Kaminskis

To cite this article: Silja Märdla, Jonas Ågren, Gabriel Strykowski, Tõnis Oja, Artu Ellmann, René Forsberg, Mirjam Bilker-Koivula, Ove Omang, Eimuntas Paršeliūnas, Ivars Liepinš \& Jānis Kaminskis (2017): From discrete gravity survey data to a high-resolution gravity field representation in the Nordic-Baltic region, Marine Geodesy, DOI: 10.1080/01490419.2017.1326428

To link to this article: http://dx.doi.org/10.1080/01490419.2017.1326428

Accepted author version posted online: 04 May 2017.

Submit your article to this journal \lceil

View related articles

View Crossmark data \lceil 


\section{ACCEPTED MANUSCRIPT}

From discrete gravity survey data to a high-resolution gravity field representation in the Nordic-Baltic region

Silja Märdla ${ }^{1}, J_{\text {Jonas }}$ Ågren ${ }^{2}$, Gabriel Strykowski ${ }^{3}$, Tõnis Oja ${ }^{4}$, Artu Ellmann ${ }^{1}$, René Forsberg ${ }^{3}$, Mirjam Bilker-Koivula $^{5}$, Ove Omang ${ }^{6}$, Eimuntas Paršeliūnas ${ }^{7}$, Ivars Liepinš ${ }^{8}$, Jānis Kaminskis ${ }^{9}$

${ }^{1}$ Faculty of Civil Engineering, Tallinn University of Technology, Tallinn, Estonia

${ }^{2}$ Lantmäteriet, The Swedish Mapping, Cadastral and Land Registration Authority, Gävle, Sweden

${ }^{3}$ National Space Institute, Technical University of Denmark, Lyngby, Denmark

${ }^{4}$ Estonian Land Board, Tallinn, Estonia

${ }^{5}$ Finnish Geospatial Research Institute, National Land Survey of Finland, Masala, Finland

${ }^{6}$ Norwegian Mapping Authority, Hønefoss, Norway

${ }^{7}$ Department of Geodesy and Cadastre, Vilnius Gediminas Technical University, Vilnius, Lithuania

${ }^{8}$ Latvian Geospatial Information Agency, Riga, Latvia

${ }^{9}$ Riga Technical University, Riga, Latvia

Correspondence: Silja Märdla, Ehitajate tee 5, 19086, Tallinn, Estonia, silja.mardla@ttu.ee

Deduction of a regularly spaced gravity anomaly grid from scattered survey data is studied, addressing mainly two aspects: reduction of gravity to anomalies and subsequent interpolation by various methods. The problem is illustrated in a heterogeneous study area and contrasting test areas including mountains, low terrain and a marine area. 


\section{ACCEPTED MANUSCRIPT}

Provided with realistic error estimates, Least Squares Collocation interpolation of Residual Terrain Model anomalies yields the highest quality gravity grid. In most cases, the Bouguer reduction and other interpolation methods tested are equally eligible. However, spline based interpolation should be avoided in marine areas with track wise survey data.

Keywords

gravity database, gridding, interpolation, residual gravity anomaly, Bouguer anomaly, Residual Terrain Model (RTM) anomaly, regional geoid, Nordic Geodetic Commission (NKG) 


\section{ACCEPTED MANUSCRIPT}

\section{Introduction}

Although Global Geopotential Models (GGM) have become increasingly detailed and accurate, there is still a need for regional (quasi)geoid models that fulfil the needs of mapping and engineering applications, especially conversion of Global Navigation Satellite System (GNSS) derived ellipsoidal heights into conventional (physical) heights with respect to the sea level (as the geoid is a surface that roughly coincides with the mean sea level). Currently, the geodetic community has set the goal of achieving 5 to $10 \mathrm{~mm}$ accuracy in regional gravimetric (quasi)geoid modelling, imposing thus strict requirements not only on the modelling techniques but also on the input gravity data.

Even though there are (quasi)geoid determination methods that can be applied directly without prior gridding of input gravity data (such as Tscherning 1985), many modelling techniques (such as Haagmans, de Min, and Gelderen 1993; Forsberg and Sideris 1993; Li and Sideris 1997; Sjöberg 2003; Ellmann and Vaníček 2007) need a regularly spaced gravity anomaly grid that has to be determined from the scattered survey data that are located from a few hundreds of meters up to a few tens of kilometres apart.

Importantly, geoid modelling is not the only application for gravity (anomaly) grids, these are also needed for other geosciences. For example, different gravity anomalies (free-air, simple Bouguer, complete Bouguer, slab-residual, mantle Bouguer etc., see e.g. Hackney and Featherstone 2003; Radhakrishna, Lasitha, and Mukhopadhyay 2008) are used in two- or threedimensional inverse as well as forward modelling by various techniques to interpret variations in mass and density that reflect the structure of solid Earth. Gravity field derivatives such as 


\section{ACCEPTED MANUSCRIPT}

gradients also reveal density contrasts (Elkins 1951). Numerous contributions similar to Mandal et al. (2015); Baptiste et al. (2016); Klitzke et al. (2016) etc. describe and interpret the gravity field and geophysical features of specific regions. For the user of a regularly spaced gravity anomaly grid, it is beneficial to be familiar with the basis upon which such a grid can be constructed and also be aware of limiting factors in grid accuracy.

Regional scale gravity database analysis and gridding are reported in Gil and RodríguezCaderot 1998; Hinze et al. 2005; Vergos et al. 2005; Jekeli, Yang, and Kwon 2009; Martín et al. 2009; Saleh et al. 2013; Véronneau 2013. Although gravity anomaly gridding is a task often performed, it is rarely discussed in detail. Generally a method is chosen according to previous experience, popularity or software availability. Sometimes the choice is based on further analysis which is not reported upon in scientific literature. Accordingly, this contribution will analyse various methods of gravity gridding to determine their advantages and shortages. A general remove-interpolate-restore (RIR) process is used. That is, the gravity anomaly point values are reduced, interpolated and then restored to result in a surface gravity anomaly grid. In further text, the entire RIR process is referred to as "gridding" interchangeably.

A number of different aspects of gravity data processing are discussed. Most importantly, two different gravity reduction/restoration methods (Sec. 2) and four different interpolation methods (Sec. 3) will be described and compared. All of these methods are known and often used, see the reference list. However, this contribution aims at offering a consistent comparison and evaluation of some gravity reduction and interpolation methods that could be used over large and challenging study areas. 


\section{ACCEPTED MANUSCRIPT}

In addition, the entire work flow of gravity data processing together with the effect of some alternative processing choices (such as omitting/incorporating certain reduction options, data weighting or changing the degree and order of the GGM used) will be discussed in detail. The current status (coverage and quality) of the North-European gravity data is reviewed, also illustrating the possible ways of solving gravity data unification issues in the context of a multination geoid modelling study covering both land and marine areas.

The different methodological approaches and subsequent results achieved over the study area may be useful for any regional gravity gridding exercise worldwide. However, the quality of the actual result is dependent on many circumstances, including gravity data coverage, distribution, accuracy, gravity field properties (rough vs. smooth) etc. These issues will be discussed in appropriate sections of this contribution.

The research reported in this contribution is an input to the Nordic Geodetic Commission (NKG) geoid modelling project ( $\mathrm{gren}$ et al. 2015; 2016) which aims at calculating a highresolution and accurate regional gravimetric quasigeoid model over the Nordic and Baltic countries in Europe, embedding also the Baltic Sea, North Sea and a large portion of the Arctic Ocean. Parts of the research area are topographically varying and data coverage is rather heterogeneous (see Sec. 5), challenging the choice of uniform modelling methods for the entire research area comprising of marine and dry land parts.

The specific area of interest has been subject to NKG geoid modelling projects since the mid 1980's. The succession of NKG geoid models include NKG-86 (Tscherning and Forsberg 1986), NKG-89 (Forsberg 1991), NKG-96 (Forsberg, Kaminskis, and Solheim 1997), NKG2002 


\section{ACCEPTED MANUSCRIPT}

and NKG2004 (Forsberg, Strykowski, and Solheim 2004). These regional geoid models were often adapted as national geoid models or height correction surfaces by fitting to a set of national GNSS/levelling points. In addition to NKG geoid models, parts of this region have been subject to other gravity field and geoid modelling studies such as Vermeer (1994); Noréus, Nyborg, and Hayling (1997); Korhonen et al. (1999); Omang and Forsberg (2000); Omang and Forsberg (2002); Ellmann (2002; 2005); Jürgenson (2003); Nahavandchi, Soltanpour, and Nymes (2005);

Lysaker et al. (2007); Ågren, Sjöberg, and Kiamehr (2009); Ågren (2009); Denker et al. (2009); Bilker-Koivula (2010); Ellmann, Oja, and Jürgenson (2011); Omang, Tscherning, and Forsberg (2012); Bilker-Koivula (2014); Märdla et al. (2015).

The NKG geoid modelling activities have contained extensive data improvements and preliminary computations. The NKG gravity database has been modernised, thoroughly updated and quality checked. A new regional high-resolution Digital Terrain Model (DTM) and an ice thickness model have been compiled. The used datasets were, if possible and meaningful, transformed into common reference frames. Preliminary grid compilations were made independently by a number of geoid computation centres, using different methods, software packages and strategies (Ågren et al. 2015). It was decided that certain aspects of gravity gridding should be further investigated before the final geoid computations. This triggered the present study and also affected the choice of reduction and gridding methods tested.

This contribution is organised as follows. First, the gravity reduction (Sec. 2) and interpolation (Sec. 3) methods together with data requirements for accurate geoid computation (Sec. 4) are explained. Second, the study area is introduced (Sec. 5) leading to a description of 


\section{ACCEPTED MANUSCRIPT}

experimental gravity gridding (Secs. 6 and 7). The results are then analysed (Sec. 8) and presented in the context of quasigeoid modelling (Sec. 9). Finally, conclusions are drawn from the findings of this study (Sec. 10).

\section{Gravity reductions for interpolation}

Interpolating the surface gravity values $g$ directly is inaccurate as the gravity field contains high frequency information due to the topography (or bathymetry), making it difficult for interpolation algorithms to estimate the correct gravity values at the grid nodes. A gravity reduction process converts the gravity point data values so that these are more reliable for prediction at desired locations.

Thus, the surface gravity anomalies need to be first reduced. After reduction, the scattered point values are interpolated into a regular grid leading to a reduced gravity grid. To obtain the surface gravity anomaly grid, there has to be a corresponding restoration process. Importantly, the restore step adds to gravity data gaps either higher or lower frequency information from reference sources like the DTM, GGM or other relevant corrections.

The used anomaly types and applied corrections are reviewed below. Besides the two reduction schemes tested in this contribution, there are others that could be used. These include mainly isostatic reductions such as the Airy-Heiskanen or the Pratt-Hayford reduction that could improve the gridding outcome over land or ocean areas respectively. 


\section{ACCEPTED MANUSCRIPT}

\subsection{Free-air anomalies}

It is assumed that the gravity value $g$ on or above the topography in the point $P$ and the corresponding (normal or orthometric) height $H_{P}$ is known. As a first step, the free-air or surface gravity anomaly $\Delta g^{F A A}$ is computed by (Heiskanen and Moritz 1967, Eq. 8--7):

$$
\Delta g_{P}^{F A A}=g_{P}-\gamma_{Q}
$$

where $\gamma_{Q}$ is the normal gravity in the point $Q$ at the height $H_{P}$ (reckoned from the reference

ellipsoid) and is computed by using standard formulas for the GRS-80 normal gravity field, cf. Moritz (2000).

Although reduced in magnitude (compared to the initial gravity value itself), the free-air anomaly field can still be quite rough and correlated with height. It is smoother in marine areas, but significant variations in the bathymetry (not considered in this study) may result in a comparatively rough field also there. Thus, a further reduction of gravity anomalies is often needed to yield a smoother anomaly field.

\subsection{Simple and complete Bouguer anomalies}

Removing the gravitational effect of an infinite planar Bouguer plate leads to the simple Bouguer anomaly $\Delta g^{S B A}$ by (Heiskanen and Moritz 1967, Eq. 3--19):

$$
\Delta g_{P}^{S B A}=\Delta g_{P}^{F A A}-2 \pi G \rho H_{P}
$$




\section{ACCEPTED MANUSCRIPT}

where $G$ is the gravitational constant and $\rho$ is the topographic density (if approximated to $2670 \mathrm{~kg} \cdot \mathrm{m}^{-3}$ then the last term in the right-hand side becomes $0.1119 H_{P}$ ).

In areas of flat terrain, $\Delta g^{S B A}$ can be a useful quantity for gridding. However, in mountainous regions the $\Delta g^{S B A}$ field can be too biased for a meaningful interpolation (Janák and Vaníček 2005). Therefore, further reduction into planar complete Bouguer anomaly $\Delta g^{C B A}$ is obtained by (Heiskanen and Moritz 1967, Eq. 3--21):

$$
\Delta g_{P}^{C B A}=\Delta g_{P}^{S B A}+\left.\delta g_{P}^{T}\right|_{z_{1}=H} ^{z_{2}=H_{P}}
$$

where $\delta g_{P}^{T}$ is the planar terrain correction and $H$ is the height of the moving integration point (determined from a DTM). Note that the alternative spherical Bouguer anomalies (see e.g. Vaníček, Novák, and Martinec 2001; Vaníček et al. 2004; Novák et al. 2001; Kuhn, Featherstone, and Kirby 2009) are not considered in this contribution.

The terrain correction $\delta g_{P}^{T}$ can be computed using different approximations. In the context of the remove-interpolate-restore technique, there is no need to extend the integration too far from the computation point $P$. The terrain correction is thus calculated by summing the attraction of a finite number of prisms according to (Forsberg 1984):

$$
\delta g_{P}^{T}=-G \times \sum \int_{x=x_{1}}^{x_{2}} \int_{y=y_{1}}^{y_{2} z z_{1}} \int_{z_{1}}^{z_{2}} \rho \times \frac{\left(z-z_{P}\right)}{\left(\left(x-x_{P}\right)^{2}+\left(y-y_{P}\right)^{2}+\left(z-z_{P}\right)^{2}\right)^{3 / 2}} d x d y d z
$$




\section{ACCEPTED MANUSCRIPT}

where $x_{P}, y_{P}, z_{P}$ and $x, y, z$ are the local Cartesian coordinates of the computation point $P$ and the moving integration element, respectively. The $z$ coordinate is the "up" direction, the limits $x_{1}, x_{2}, y_{1}, y_{2}$ are constants for each prism. Most commonly, only flat top prisms are used, i.e. $z_{1}$ and $z_{2}$ are also constant for each prism. The way $z_{1}$ and $z_{2}$ are chosen is indicated by the type of notation used in Eq. 3. Again, due to lack of density information available, $\rho$ is usually taken to be constant.

In the present study, the curvature of the Earth is taken into account by shifting each prism downwards by correcting the integration constants of Eq. 4 as (Forsberg 1984, p. 111):

$$
z_{1}^{*}=z_{1}-\frac{s^{2}}{2 R} ; z_{2}^{*}=z_{2}-\frac{s^{2}}{2 R}
$$

where $s$ is the distance between the computation point $P$ and the integration point, $R$ is the mean radius of the Earth. Admittedly, this is a crude way to take the Earth's curvature into account, but accurate enough in the context of the present study where the topographic corrections in question are used only for the remove-interpolate-restore process.

\subsection{Residual Terrain Model (RTM) anomalies}

An alternative to the Bouguer reduction described in the previous section is to reduce the free-air anomaly field by a band-pass filter that attenuates signals above and below a desired frequency. The free-air anomaly values can be reduced in the long-wavelength spectrum by removing the gravity contribution of a GGM and in the short-wavelength spectrum by removing the contribution of a Residual Terrain Model (RTM) by: 


\section{ACCEPTED MANUSCRIPT}

$$
\Delta g_{P}^{R T M A}=\Delta g_{P}^{F A A}-\Delta g_{P}^{G G M}-\delta g_{P}^{R T M}
$$

where $\Delta g_{P}^{G G M}$ is the gravity anomaly from a GGM evaluated to a suitable maximum degree and $\operatorname{order}(\mathrm{d} / \mathrm{o})$ and $\delta g_{P}^{R T M}$ is the topographic effect of the RTM reduction computed as (cf. Forsberg 1984):

$$
\delta g_{P}^{R T M}=2 \pi G \rho\left[H_{P}-H_{P}^{r e f}\right]-\left[\left.\delta g_{P}^{T}\right|_{z_{1}=H_{P}} ^{z_{2}=H}-\left.\delta g_{P}^{T}\right|_{z_{1}=H_{P}^{r e f}} ^{z_{2}=H^{\text {ref }}}\right]
$$

where $H^{\text {ref }}$ is the height of a smooth reference surface; $\left.\delta g_{P}^{T}\right|_{z_{1}=H_{P}} ^{z_{2}=H}$ and $\left.\delta g_{P}^{T}\right|_{z_{1}=H_{P}^{z_{2}}=H^{\text {ref }}} ^{\text {ref }}$ denote the terrain correction for the topographic surface and the reference surface respectively. Note that Eq. 7 does not demand the use of the so-called harmonic correction (Forsberg 1997, Sec. 2.32.4). The reference elevation surface can be any smooth surface representing mean elevations in the area. It is often constructed by averaging the fine resolution DTM grid and then low-pass filtering this by taking moving averages of an appropriate number of adjacent blocks. Or alternatively, a spherical harmonic representation of either the regional or an independent global DTM is evaluated to a d/o that corresponds to the desired smoothness. For related studies, see e.g. Hirt $(2010,2013)$ and references therein. 


\section{ACCEPTED MANUSCRIPT}

\subsection{Atmospheric and ice corrections}

For both of the gravity reduction processes described above, the atmospheric and ice correction (denoted below by superscript $A$ or $I$, respectively) can be applied. Again, these are applied before and removed after gridding.

The atmospheric correction accounts for the gravitational effect of the atmospheric masses, much as the terrain correction accounts for the topographic masses. This effect can be computed by an empirical formula of DMA (1987, Eq. 4--23):

$$
\delta g^{A}=0.87 \times e^{-0.116 \times H^{1.047}}
$$

where $e \approx 2.718, \delta g^{A}$ is in mGal and $H$ is in $\mathrm{km}$. The resulting numerical values are similar to the recommendations given in Moritz (2000). This correction cannot exceed $0.87 \mathrm{mGal}$, that is, the effect of atmospheric masses on the sea level.

$\delta g^{A}$ is added to the surface gravity anomaly point values and subtracted (in gridded form) after interpolation.

The ice correction is needed since the Bouguer and RTM corrections are initially computed using topographic density and DTM heights that refer to the surface of glaciers. The ice masses are artificially filled up to reach topographic density $\rho$, at the same time as the AiryHeiskanen isostatic compensation is taken into account (e.g. Sünkel 1986). After interpolation, the reduction is reversed, leading back to ice density (masses are moved back to where they 


\section{ACCEPTED MANUSCRIPT}

originate from). To achieve this, a residual ice mass potential $\delta V^{I}$ is defined as (e.g. Martinec 1998; Ågren 2004):

$$
\delta V_{P}^{I}=V_{P}^{I}-V_{P}^{i s o}
$$

where $V^{i s o}$ is the corresponding compensating potential according to the Airy-Heiskanen hypothesis and $V_{P}^{I}$ is the potential generated by the mass deficit of the glaciers, which is expressed by the Newton's integral in spherical coordinates as

$$
V_{P}^{I}=G\left(\rho^{I}-\rho\right) \iint_{\sigma^{I}} \int_{z=R+H^{I}-T^{I}}^{R+H^{I}} \frac{z^{2}}{S} d z d \sigma^{I}
$$

where $\rho^{I}$ is the ice density, $\sigma^{I}$ is the spatial domain covered with glaciers, $H^{I}$ is the height to the (ice) surface and $T^{I}$ is the ice thickness. Note that the density difference in Eq. 10 is assumed to be constant and that it is negative. The ice effect $\delta g_{P}^{I}$ on the surface gravity anomaly is then given by the standard boundary condition of physical geodesy:

$$
\delta g_{P}^{I}=-\frac{\partial \delta V_{P}^{I}}{\partial r_{P}}-\frac{2}{r_{P}} \delta V_{P}^{I}
$$

where $r_{P}$ is the geocentric radius of point $P$. 


\section{ACCEPTED MANUSCRIPT}

Thereafter $\delta g_{P}^{I}$ is subtracted from the surface gravity anomaly point values and added (in gridded form) after interpolation.

\section{Interpolation methods}

Most interpolation algorithms demand that the phenomenon described by the point data to be gridded could be regarded as a spatial stochastic process and the field to be homogeneous: that is, stationary (the mean would be constant over space and the covariance would be position independent) and isotropic (the spatial dependence of values would be independent of direction). The reduction processes described in Sec. 2 aim at fulfilling this requirement as rigorously as possible. However, in practice, also the reduced gravity data is somewhat non-stationary, anisotropic and contains unavoidable observation errors, resulting in various deficiencies of grids obtained by different interpolation methods.

Numerous interpolation methods could be applied in gravity gridding. The four methods described in Secs. 3.1 to 3.4 were selected as these have been demonstrated to yield reasonable gravity anomaly estimates and are also often used in similar studies.

Due to their varying nature, each method reveals different characteristics. Two methods (Secs. 3.1 and 3.2) are simple and fast deterministic methods that generate a spline-based surface. The other two (Secs. 3.3 and 3.4) are stochastic methods that demand a priori information about the spatial correlation and quality of the data. In different ways, all four interpolation methods allow the resulting gravity anomaly surface to deviate from input data, thus accounting for inaccuracies of the input data. 


\section{ACCEPTED MANUSCRIPT}

\subsection{Continuous curvature splines}

According to this method, the gridded values $z_{P}$ (functions of grid node coordinates $x_{P}, y_{P}$ ) are computed by solving:

$$
(1-T) \times L\left[L\left(z_{P}\right)\right]+T \times L\left(z_{P}\right)=0
$$

where $0<T<1$ is a tension factor and $L$ is the Laplace operator. $T=1$ results in a surface where maxima and minima are achievable only at data point locations while $T=0$ results in a minimum curvature solution (Smith and Wessel 1990).

The continuous curvature splines interpolation method has been implemented in the Generic Mapping Tools (GMT, Wessel et al. 2013) sub-program surface and will hereafter be referred to as SURF. The default tension factor suggested by the program's manual for interpolation of potential field data is $T=0.25$.

The SURF method is expected to generate a smooth gravity grid. However, in previous experience, it has shown some unreasonable undulation in larger data gaps, next to steep gradients and near the borders of input data area. It is possible to reduce the latter deficiency by setting the tension factor to 0 outside the research area. Another drawback of the SURF method is that it computes the $z$ values on a planar surface. Thus the Earth's curvature induced errors may become significant over larger research areas. Third, the uniformly chosen tension factor may not represent the behaviour of the gravity field in all areas equally well. Note that, for 


\section{ACCEPTED MANUSCRIPT}

practical purposes, the resulting grid has to be uniform and seamless. Therefore varying the tension factor manually according to different sub-areas is not a feasible option.

\subsection{Spherical interpolation in tension}

According to this method, a Delaunay triangulation on a sphere (e.g. Renka 1997a) is performed on input data. Then, given a certain tension factor (determined automatically from local or global gradients) for each triangle side and arc containing the interpolation point and connecting a triangle vertex to the opposite side, a value is interpolated to the new point contained within that specific triangle, see e.g. Renka (1997b). Such a spherical interpolation in tension algorithm has been implemented in the GMT sub-program sphinterpolate and will hereafter be referred to as SPHI.

As this method is rather similar to the SURF method, it is expected to yield similar results, desirably improved by the high degree of automation in choosing the tension parameters and by accounting for the Earth's spherical geometry.

\subsection{Least Squares Collocation}

In the Least Squares Collocation (LSC) method, the gridded gravity anomaly values are obtained by solving the following matrix equation (Moritz 1980, Eq. 14.27):

$$
\Delta g_{P}=C_{\Delta g_{P} \Delta g}\left(C_{\Delta g \Delta g}+D\right)^{-1} \Delta g
$$




\section{ACCEPTED MANUSCRIPT}

where $\Delta \boldsymbol{g}$ is the vector of known (surveyed) anomaly point values, $\Delta \boldsymbol{g}_{P}$ is the vector of unknown (grid) values, $\boldsymbol{C}_{\Delta g \Delta g}$ is the auto-covariance matrix of the $\Delta \boldsymbol{g}$ values, $\boldsymbol{C}_{\Delta g_{p} \Delta g}$ is the cross-covariance matrix of the $\Delta \boldsymbol{g}$ and $\Delta \boldsymbol{g}_{P}$ values and $\boldsymbol{D}$ is the noise variance-covariance matrix. For further details, see (Moritz 1980, Sec. 14). LSC is implemented in the GEOGRID sub-program of the GRAVSOFT research software package (Forsberg and Tscherning 2008).

Importantly, for such an interpolation approach, the spatial dependence of the data in question is described by the covariance matrices and needs to be estimated from the survey data. This can be achieved by fitting a theoretical model to empirical covariance values. In this study, a second order Markov model is used (Sansò and Sideris 2013, Eq. 9.34):

$$
C(l)=C_{0}\left(1+\frac{l}{\alpha}\right) e^{-l / \alpha}
$$

where $C(l)$ is the modelled covariance value over the distance $l, C_{0}$ is the signal variance and $\alpha$ is a constant related to the correlation length $X_{1 / 2}$ approximately as $\alpha=0.595 X_{1 / 2}$. The correlation length $X_{1 / 2}$ is here defined as the distance at which the covariance function reaches the value of $C_{0} / 2$.

In addition, individual point weighting can be done using a priori standard deviation values supplied together with the gravity data, assuming that the variance-covariance matrix $\boldsymbol{D}$ in Eq. 13 is diagonal. 


\section{ACCEPTED MANUSCRIPT}

As an advantage, a formal error grid can be determined together with the LSC predictions. Being a powerful and flexible interpolation method, the LSC is expected to perform well in areas that correspond to the average correlation properties estimated. Unfortunately, a single covariance function is unable to fully describe a heterogeneous or anisotropic dataset, which is a rather common situation in gravity anomaly gridding. Research on the so-called nonstationary covariance function modelling is ongoing, see the detailed overview in Darbeheshti and Featherstone (2009).

\subsection{Kriging}

Kriging (Krige 1951, for a recent review see e.g. Cressie 2015) is an interpolation method that is similar to the concepts of LSC, for their differences see e.g. Dermanis (1984).

In the current study, Kriging is implemented using a different covariance function than for LSC. Namely, the spherical semi-variogram model $S V(l)$ (Isaaks and Srivastava 1989, Eq. 16.6) is used:

$$
S V(l)=\left\{\begin{array}{c}
c_{0}+\left[C_{0}-c_{0}\right]\left[\frac{3 l}{2 A}-\left(\frac{l}{2 A}\right)^{3}\right], \text { if } l \leq A \\
C_{0}, \text { if } l>A
\end{array}\right.
$$

where $c_{0}$ is the nugget effect and $A$ is a length parameter corresponding to the range after which data are presumably no longer correlated. Note that the parameter $A$ can be modified to account for the anisotropy effect. In the simplest case of the anisotropy angle being $0^{\circ}, A$ is divided by 


\section{ACCEPTED MANUSCRIPT}

the anisotropy ratio. The semi-variogram values are related to the covariance values by

$$
C(l)=C_{0}-S V(l)
$$

Kriging has many forms. In this study, Ordinary Kriging without a drift function implemented in the Surfer software (Golden Software LLC 2016) is used. This interpolation method will hereafter be referred to as KRIG.

\section{Propagation of terrestrial gravity data errors into geoid modelling}

The data related error of a (quasi)geoid model comprises of omission error (the lacking information with higher frequency than the model resolution) and commission error (errors in the existing data). The latter can in turn be separated into uncorrelated (white noise) and correlated (systematic) parts.

The uncorrelated commission error has a relatively small effect as positive and negative errors tend to cancel out. The most dangerous are long-wavelength systematic effects because the (quasi)geoid has most power in long wavelengths. This is illustrated by the spectral relationship of the geoidal undulation to gravity anomalies over the entire globe (e.g. Goos et al. 2003, Eq. 1):

$$
N_{n}=\frac{R}{\gamma_{0}(n-1)} \Delta g_{n}
$$




\section{ACCEPTED MANUSCRIPT}

where $N_{n}$ is the $n$-th degree surface spherical harmonic of the geoid height, $R$ is the mean Earth radius, $\gamma_{0}$ is normal gravity on the surface of the reference ellipsoid and $\Delta g_{n}$ is the $n$-th degree surface spherical harmonic of the gravity anomaly.

In the simplified case of a sufficiently small spherical disc, the influence $\epsilon_{N}$ of a systematic gravity data error $\epsilon_{g}$ on the geoidal height $N$ can roughly be estimated by (cf. Heiskanen and Moritz 1967, Eq. 2-234):

$$
\epsilon_{N}=\frac{S}{g_{P}} \epsilon_{g}
$$

where $g_{P}$ is the gravity value at the computation point and $S$ is polar distance. For instance, the presence of a $0.1 \mathrm{mGal}$ gravity bias within a $100 \mathrm{~km}$ radius around the computation point yields a geoid error in the order of $1 \mathrm{~cm}$.

Commonly, the Stokes (1849) formula is used to compute a gravimetric geoid from the gravity data. It can be modified so as to obtain the long wavelength (global) information from a GGM (see e.g. Vaníček and Sjöberg 1991) that is more accurate than the terrestrial data in the long wavelength spectrum. This alleviates the danger of having systematic errors in the regional gravity database. Nevertheless, since gravity data have usually been collected over long periods of time with varying accuracy and following different national conventions, it would be beneficial to analyse these in order to detect and eliminate systematic errors as much as possible, e.g. by a method in Saleh et al. (2013, Sec. 3) or Wang et al. (2012, Sec. 4.4). 


\section{ACCEPTED MANUSCRIPT}

Gravity point accuracy may currently be at the level of $5 \mu \mathrm{Gal}$ for absolute gravimetry (Niebauer et al. 1995) and 20 to $100 \mu \mathrm{Gal}$ for relative gravimetry surveys. However, as terrestrial gravity surveys are labour-intensive, a dense enough coverage of sufficient quality data is not available everywhere. Especially coastal and marine areas have gravity coverage of significantly lower quality and density (see e.g. Featherstone 2009).

A recent summary on the practical data requirements for a $1 \mathrm{~cm}$ geoid can be found in Denker (2013, sec. 4.1.), see also references therein. It is concluded that gravity data need to be connected to a highly accurate gravity network (in the order of $0.01 \mathrm{mGal}$ ) while single observation accuracy of about $1 \mathrm{mGal}$ is sufficient.

Ågren and Sjöberg (2014) show that a 5 mm geoid can be achieved within a mediumsize country (Sweden) if the gravity anomaly data with uncorrelated noise below $0.5 \mathrm{mGal}$ and systematic errors below $0.1 \mathrm{mGal}$ are available on at least $5 \mathrm{~km}$ resolution with no data gaps in the computation area or its vicinity. As this conclusion depends on the roughness of the gravity field, it is not necessarily general. For instance, the extremely rough gravity field in mountainous areas most likely requires a significantly denser gravity sampling.

\section{Study area}

In the NKG geoid modelling project the quasigeoid is computed for the area of $53^{\circ}$ to $73^{\circ} \mathrm{N}, 0$

${ }^{\circ}$ to $34^{\circ}$ E. This covers the territory of Denmark, Norway, Sweden, Finland, Estonia, Latvia and Lithuania plus the surrounding areas, including the Baltic Sea, North Sea and large parts of the Arctic Ocean (cf. Fig. 1). The gravity data from the NKG database cover the area of $52^{\circ}$ to $74^{\circ}$ 


\section{ACCEPTED MANUSCRIPT}

$\mathrm{N},-2^{\circ}$ to $36^{\circ} \mathrm{E}$. It is a heterogeneous region covering both land and marine areas. Norway has a rugged terrain with deep fjords and heights exceeding $2 \mathrm{~km}$ while in Denmark and the Baltic countries (Estonia, Latvia, Lithuania) the topographic heights only reach a few hundred meters, see Fig. 1.

The NKG gravity database holds data submitted by participating countries for NKG geoid modelling purposes only. The information is stored as "publications" (groups of observations submitted together) that have various amounts of meta data in the form of a report or short description. Most publications include a single approximate error estimate while some newer ones contain individual and well reasoned error estimates for each data point. The distribution and estimated accuracy of gravity data in the NKG database is shown in Figs. 2 and 3 , relevant characteristics are summarized in Table 1 .

. According to Sec. 4, the average gravity coverage (that corresponds to a distance of about $3.5 \mathrm{~km}$ between neighbouring points) could be sufficient for computing a geoid model with an accuracy of 5 to $10 \mathrm{~mm}$. However, the average a priori error estimate of gravity data is about $2.3 \mathrm{mGal}$ which is not up to the aforementioned requirements.

To illustrate the differences in gravity field modelling methods, three test areas of $1^{\circ}$ by

$2^{\circ}$ with contrasting characteristics that could commonly occur in any regional gravity field study were selected. Area $1\left(61^{\circ}\right.$ to $62^{\circ} \mathrm{N}, 6^{\circ}$ to $8^{\circ} \mathrm{E}$, Figs. $4 \mathrm{a}$ and $\left.5 \mathrm{a}\right)$ was selected in the Sognefjord area, Norway. Sognefjord is a $200 \mathrm{~km}$ long and, on average, $4.5 \mathrm{~km}$ wide fjord with depths up to $1300 \mathrm{~m}$ surrounded by rugged cliffs. Area $2\left(58.5^{\circ}\right.$ to $59.5^{\circ} \mathrm{N}, 25^{\circ}$ to $27^{\circ} \mathrm{E}$, Figs. $4 \mathrm{~b}$ and $5 \mathrm{~b}$ ) was selected in central Estonia with flat terrain and unusually dense coverage of 


\section{ACCEPTED MANUSCRIPT}

accurate gravity data. Area $3\left(55^{\circ}\right.$ to $56^{\circ} \mathrm{N}, 6^{\circ}$ to $8^{\circ} \mathrm{E}$, Fig. $\left.5 \mathrm{c}\right)$ was selected in the marine area West of Denmark containing ship gravimetry tracks only. The data statistics for these test areas can also be found in Table 1.Area 2 is an example of very good gravity coverage and quality that comfortably fulfils the requirements discussed in Sec. 4 while Area 1 and 3 have similar statistics to the entire NKG area.Sec. 4 also stresses the importance of eliminating systematic long wavelength errors. In the current study, it was assumed that, due to the great care taken in preparing the NKG database by representatives of the participating countries, such errors would be minimal, at least on land of the Nordic-Baltic countries. An example of examining national data for the presence (and elimination) of systematic errors within the current study area can be found in Ellmann, All, and Oja (2009).

For gravity data processing and evaluation, it is necessary to possess, in addition to the gravity survey values and positions, some supplementary information. First, a high-resolution DTM is necessary for terrain correction computation by Eq. 4. Second, a GGM is needed for generating a reference gravity field used in Eq. 6. Optionally, co-located GNSS and levelling points can be used for geometric geoid determination for comparison with the gravimetric geoid models derived from the gravity grids.

As the current research was aimed at the NKG2015 geoid modelling project, it made use of the $3 " \times 3$ " NKG DEM 2014, which in the present study was further averaged to $0.001^{\circ}$ $\times 0.002^{\circ} \approx 3.6 " \times 7.2^{\prime \prime}$ (Fig. 1) and 2538 GNSS/levelling points specially compiled by participating countries. Additionally, the project specification allowed for the use of either the 


\section{ACCEPTED MANUSCRIPT}

high-degree EIGEN-6C4 (Förste et al. 2015) or the satellite-only GO_CONS_GCF_2_DIR_R5 (Bruinsma et al. 2013) global geopotential model.

\section{Preprocessing gravity data}

In this section, numerous steps of data preprocessing are described. It illustrates possible ways of solving unification issues of a heterogeneous gravity dataset and could be of reference to other geoscientists working on similar tasks.

\subsection{Reference systems}

When working with gravity data from different sources, it is first necessary to make sure that their horizontal positions, heights and gravity values are in the same reference frames and include the same, compatible corrections (e.g. tidal, atmospheric). In areas with significant geodynamic motions, like the postglacial land uplift in the Nordic-Baltic region, it is also important to choose a common reference epoch. Although small in magnitude, the errors introduced by inconsistencies in the above are systematic and widespread, thus of importance in geoid modelling (see Eqs. 17-18).

In the NKG2015 geoid modelling project, it was set as a goal to transfer datasets of different nations into uniform reference systems/frames. A common postglacial land uplift epoch of 2000.0 and the zero permanent tide system was selected. The gravity values are given in the official national gravity systems based on either modern absolute gravimetry or on the International Gravity Standardisation Net 1971 (IGSN71, Morelli et al. 1971), in the latter case, 


\section{ACCEPTED MANUSCRIPT}

with a correction to convert from the mean tide to zero permanent tide system. Atmospheric corrections are not included in the NKG gravity database. Point positions are expressed in the national European Terrestrial Reference System (ETRS) 89 realisations and the normal heights in the national European Vertical Reference System (EVRS) realisations. More details on the NKG2015 geoid modelling project are available in Ågren et al. (2015; 2016).

\subsection{Update and analysis of the NKG gravity database}

Data updating for the NKG2015 geoid model project consisted of revising all the information in the NKG gravity database, cleaning or removing overlapping datasets and replacing or updating with new data in the correct reference systems/frames, permanent tide system and postglacial land uplift epoch. It was the responsibility of national representatives to decide which data to preserve and also to quality check all the remaining data within the country.

The above rather challenging requirements on reference systems, etc., unintentionally, resulted in some large data voids. After extensive analysis, an exception was made for instance to parts of publication no. 345 that cover data void areas East of the Latvian border. The filling of this void affected the resulting quasigeoid model by around $2 \mathrm{~cm}$ in Eastern Latvia.

The Nordic and Baltic countries are surrounded by marine areas that possess significant variations in gravity signal which can affect the gridding result also in coastal areas. Therefore an effort has been made over the past decades to cover these areas with terrestrial, shipborne, airborne and on-ice gravimetric data.

When updating the gravity database, a bias was found and corrected between two marine datasets in Skagerrak, the strait between Norway and Denmark. Another problematical area is 


\section{ACCEPTED MANUSCRIPT}

the Eastern part of Gulf of Finland (GOF) where there are practically no terrestrial/marine data available in an area of about $20000 \mathrm{~km}^{2}$. It is not clear if there have ever been any surveys. Regardless, these are not available to the NKG community. Yet, information from this area directly affects the gravity gridding and subsequent quasigeoid modelling in Southern Finland and Northern Estonia, the region of intense shipping and economical activities. Therefore, to fill the data void in the Eastern part of GOF, a patch was generated by evaluating the GO_CONS_GCF_2_DIR_R5 GGM up to d/o 240 at empty cells of $0.01^{\circ}$ by $0.02^{\circ}$ in the area of $59^{\circ}$ to $62^{\circ} \mathrm{N}$ and $25^{\circ}$ to $30^{\circ} \mathrm{E}$.

Further improvements in gravity coverage over the marine areas are expected within the frames of the ongoing Finalising Surveys for the Baltic Motorways of the Sea (FAMOS Consortium 2014) international cooperation project.

In the context of gravity gridding, it is important to notice that the distribution of data varies on land and sea. Gravity points surveyed on land are rather uniformly distributed while marine data are gathered along ship tracks. For the optimum gridding results, these would demand different interpolation approaches. For example, the SURF and SPHI algorithms may generate unnecessary undulations or large extrema in the relatively large data gaps between tracks. This is likely a result of the selected tension factor allowing the spline surface to undulate with a larger amplitude than appropriate. The alternative statistical LSC and KRIG methods using a covariance function to model the spatial dependence of gravity values can also start undulating between tracks. Consider the following example: marine tracks are separated by 100 $\mathrm{km}$ and the spatial correlation goes to (nearly) zero in, say, $30 \mathrm{~km}$, then the resulting gravity 


\section{ACCEPTED MANUSCRIPT}

anomaly grid may contain artificial stripes. The actual performance of interpolation algorithms in marine areas will be analysed in Sec. 8 .

\subsection{Automatic blunder detection}

Plotting and visual inspection of data and their derivatives (such as the reduced gravity field in this case) can help detect gross errors, see e.g. Vergos, Tziavos, and Andritsanos (2005, sec. 2.2). However, larger datasets need a more automatic approach. A simple, yet effective, method for automatic detection of outliers can be leave-one-out cross validation (CV). CV limits are, however, very dependent on the spatial variability of the modelled quantity. Therefore, it is best used after the reduction of gravity anomaly values (see Sec. 2) to assure a minimally and homogeneously varying quantity across the entire research area.

Nevertheless, it is challenging to find a uniform cross validation limit suitable for a heterogeneous area. In the current research area, CV limits as high as 20 to $30 \mathrm{mGal}$ remove as many as 0.1 to $1 \%$ of the total points. Most of these are located in the rugged landscape such as the Norwegian mountains and clearly represent the actual gravitational signal. Meanwhile, no points are removed over the other areas, where a much lower CV limit would be needed.

Certainly, automatic cross validation with a fixed limit across such a heterogeneous area is questionable. Recall that manual separation of the research area into sub-areas cannot be considered for practical reasons. Additionally, the reduced gravity fields computed as described in Sec. 2.2 or 2.3 have different characteristics, again demanding for slightly different CV limits. Therefore, means to automatically differentiate CV limits between rougher and smoother parts of the (reduced) gravity field under consideration can be investigated in further studies. Meanwhile, 


\section{ACCEPTED MANUSCRIPT}

it was decided that for the purpose of the gridding related research reported in this contribution, no cross validation will be used. This will also ensure that the different gravity anomaly grids will be comparable. Fortunately, an effort has already been made by participating countries to remove obvious gross errors from the NKG database.

\subsection{Downward continuation of airborne data}

Airborne gravimetry has proved to be a useful and fast method for covering large, sometimes hard-to-reach, areas with gravity data, for connecting different terrestrial gravity surveys and for improving the gravity field models in areas of high gravity field variability or low terrestrial point density (such as coastal and marine areas), see e.g. Bae et al. (2012); Bolkas, Fotopoulos, and Braun (2016); Tscherning, Rubek, and Forsberg (1998); Forsberg and Olesen (2010); Hwang et al. (2007). Several low-elevation airborne gravity datasets are also available over the marine parts of the study area, see the red-coloured tracks in Fig. 2.

Aerogravity values are measured at the flight altitude. Due to the attenuation effect, it is not sufficient to use the free-air gravity gradient (approx. $0.3086 H$ ) to "lower" these to the topographic surface. Instead, an additional downward continuation (DWC) correction needs to be added. After DWC, airborne data can be treated as terrestrial data. For the computation of the DWC correction, two different methods were tested.

Method 1 


\section{ACCEPTED MANUSCRIPT}

The DWC correction is taken to be equal to the free-air anomaly difference at the flight altitude and the surface by using a high degree GGM (Ellmann 2011). The EIGEN-6C4 GGM was used in numerical computations.

A drawback of this method is that it is limited to the maximum spherical harmonic degree of the GGM, that is 2190 . Also, the detailed gravity anomalies available for the regional geoid determination are not utilised. Instead, the unknown and possibly lower quality GGM derived gravity anomalies are used.

Method 2

The vertical gradient of the reduced gravity anomaly (in this study, the RTM anomaly) is estimated and used to DWC the reduced airborne data. Such a method is limited to the first linear term in the Taylor expansion of the reduced gravity anomaly with respect to the height. Also, numerical problems might occur when estimating the gradient, although the reduced field should be suitable for such a task. As opposed to Method 1, there is no limitation of the maximum spherical harmonic degree and the input information is of high quality.

The standard deviation and maximum value of the DWC corrections computed is 0.37 $\mathrm{mGal}$ and $3.3 \mathrm{mGal}$ for Method 1 and $0.47 \mathrm{mGal}$ and $8.7 \mathrm{mGal}$ for Method 2 respectively. The standard deviation of the method differences is $0.38 \mathrm{mGal}$ and the mean difference is 0.04 mGal. The larger differences occur over Denmark and Sweden, where the flight heights were much higher than over the Baltic Sea (around $1000 \mathrm{~m}$ and $250 \mathrm{~m}$ respectively). Considering that the measuring noise of these airborne datasets is around $2 \mathrm{mGal}$, such differences between the methods can be considered negligible and either method can be used. 


\section{ACCEPTED MANUSCRIPT}

\subsection{Covariance analysis}

To provide LSC or KRIG interpolation with spatial correlation information, covariance analysis was performed on the reduced (either Bouguer or RTM) gravity anomalies.

First, the entire research area was considered. Empirical covariance functions were computed for the RTM and Bouguer anomaly data, to which the second order Markov covariance functions (Eq. 14) were fitted, see Figs. 6a and 6e. Similarly, spherical semivariogram models (Eq. 15) were computed. These were later used in the LSC or KRIG interpolations respectively. For comparability, the semi-variogram models were then converted to covariance functions by Eq. 16 and also depicted in Figs. 6a and 6e.

For reference, the empirical covariances of individual test areas were also estimated, see Figs. $6 \mathrm{~b}$ to $6 \mathrm{~d}$ and $6 \mathrm{f}$ to $6 \mathrm{~g}$. Note, that separate theoretical covariance functions were not fitted for the test areas as these would not be used in the interpolation process. For the Bouguer anomalies only, the three test areas were extended by $1^{\circ}$ in the NS direction and $2^{\circ}$ in the EW direction, to increase the reliability of covariance estimation (because Bouguer anomaly correlation length is in the same order as the test area size).

These figures illustrate the variability of spatial correlation of gravity anomalies between the test areas. Judging by the fit between empirical and theoretical covariance curves, a reasonable interpolation result can be expected in Area 2 and 3 using the RTM anomalies. In case of the Bouguer anomalies, the theoretical covariance function either under- or overestimates the spatial correlation in all the test areas. 


\section{ACCEPTED MANUSCRIPT}

Table 2 lists the estimated correlation lengths $X_{1 / 2}$ for both reduction methods. It is worth noting that the correlation lengths vary less for the RTM anomalies, while these of the Bouguer anomalies vary almost three times between the test areas. Another advantage of using the (relatively short correlation length) RTM anomalies for gridding is that in larger data voids, the underlying GGM and DTM will provide the missing information instead of the interpolation algorithm attempting to estimate the values based on spatial correlation.

As a result of covariance analysis, for practical computations, the following parameters were chosen (by rounding downwards): $X_{1 / 2}=15 \mathrm{~km}$ and $A=1^{\circ}$ for the RTM anomalies; $X_{1 / 2}=70 \mathrm{~km}$ and $A=6^{\circ}$ for the Bouguer anomalies.

\section{Generating gravity anomaly grids}

Before testing the different gravity reduction and interpolation processes on the NKG gravity data, the following practical steps were taken.

First, all data with a priori error estimates $\geq 8 \mathrm{mGal}$ were excluded from the gridding. This limit corresponds to the highest realistic error estimates of the NKG gravity data.

Second, to improve interpolation quality along the edges of the area of interest, additional gravity data was derived (on a regular grid of $0.01^{\circ}$ by $0.02^{\circ}$ not closer than $0.15^{\circ}$ to any existing points) from EIGEN-6C4 GGM evaluated to its maximum d/o 2190 to fill all data gaps in the area of $51^{\circ}$ to $75^{\circ} \mathrm{N},-4^{\circ}$ to $38^{\circ} \mathrm{E}$. This was considered sufficient for the purposes of this study. However, considering the convergence of the meridians, an even larger buffer area 


\section{ACCEPTED MANUSCRIPT}

should be used for the actual geoid modelling in sub-polar latitudes. The error estimate of these fill-in points was set to $6 \mathrm{mGal}$ to comply with the typical accuracy of GGMs over the oceans (see Förste et al. 2015; Andersen 2010) and be larger than that of most observed data.

Third, the airborne observations were downward continued by Method 1 (c.f. Sec. 6.4). Fourth, multiple observations within a $50 \mathrm{~m}$ horizontal range were identified, arithmetically averaged and the standard deviation of the resulting point was taken to be equal to the minimum standard deviation input value of the multiple point cluster.

Fifth, the effect of using the atmospheric and ice corrections (see Sec. 2.4) on the resulting surface gravity anomaly grid and the subsequent quasigeoid model (computed as described in Sec. 9) was analysed. For this, a gravity anomaly grid or corresponding quasigeoid with the atmospheric or ice corrections included in gridding was subtracted from an analogous product computed without these corrections.

The effect of using the atmospheric correction (Eq. 8) in the remove-interpolate-restore process has a distinct pattern that is correlated with height. However, it is in the order of only $\pm 0.1 \mathrm{mGal}$ on the resulting surface gravity anomaly grid in the most rugged parts (Area 1 ) of the research area. The corresponding effect on the resulting quasigeoid model is certainly negligible with a standard deviation of $0.3 \mathrm{~mm}$ and the maximum difference reaching only $2 \mathrm{~mm}$.

The effect of using the ice correction (Eq. 11) in the gridding process is relevant only in the vicinity of Norwegian glaciers. In Area 1, it has a standard deviation of $1.4 \mathrm{mGal}$ with maximum differences reaching $21 \mathrm{mGal}$, where the ice thickness reaches $440 \mathrm{~m}$, see Figs. 7a 


\section{ACCEPTED MANUSCRIPT}

and $7 \mathrm{~b}$. Comparison of the resulting quasigeoid models reveals a systematic difference reaching $5 \mathrm{~cm}$ in the ice-affected area, see Fig. 7c.

Although the atmospheric correction is very small and the ice correction is significant only in Norway, both were applied in all of the test computations of the current study. Recall, that a superscript $A$ or $I$ denotes quantities that are also corrected for the atmospheric or ice effect respectively.

\subsection{Grids computed via Bouguer anomalies}

Grids computed via Bouguer anomalies were compiled in the following way:

(1) The free-air anomaly point observations $\Delta g^{F A A}$ (Fig. 8) were reduced to simple Bouguer anomalies $\triangle g^{S B A}$ according to Eq. 2. For the result, see Fig. 9a.

(2) The $\Delta g^{S B A}$ were further converted to complete Bouguer anomalies $\Delta g^{C B A}$ according to Eq. 3 by removing the terrain corrections $\delta g^{T}$ (Fig. 9b).

The terrain corrections were computed according to Eqs. 4 and 5, using the DTM grid of $0.001^{\circ}$ by $0.002^{\circ}$ to a distance of $15 \mathrm{~km}$ and the DTM grid of $0.01^{\circ}$ by $0.02^{\circ}$ to a distance of $200 \mathrm{~km}$. Practical computations within the radius of $15 \mathrm{~km}$ were done using the GRAVSOFT subprogram TC. The DTM was locally spline interpolated to fit the given height of the gravity observation in the computation point $P$ (Forsberg 1984, p. 114). The sub-program TCFOUR that speeds up the computation by Fast Fourier Transformation (FFT) convolutions was used for the distance of 15 to $200 \mathrm{~km}$. 


\section{ACCEPTED MANUSCRIPT}

(3) Since the atmospheric correction is not included in the NKG database, Eq. 8 was applied.

(4) The ice correction was applied as described in Sec. 2.4. In practice, it was computed exactly as in Ågren (2004, Chapter 6), using rectangular prisms (Eq. 4) in the vicinity (closer than $0.1^{\circ}$ in latitude and $0.2^{\circ}$ in longitude) of each computation point $P$ and spherical quadrature formulas with strict integration in the vertical (Martinec 1998, Sec. 3.8; Sjöberg 2000, Sec. 4) beyond the aforementioned limits. The ice density was set to $0.917 \mathrm{~g} . \mathrm{cm}^{-3}$, topographic density to $2.67 \mathrm{~g} . \mathrm{cm}^{-3}$ and the isostatic compensation depth was selected as $30 \mathrm{~km}$.

(5) For practical implementation of most interpolation algorithms, the scattered point data should first be low-pass filtered or averaged according to the grid step of the final grid to reduce cluttering (or high frequency information) that results in aliasing.

Therefore, the point data to use were then selected so that a single point with the smallest a priori error estimate was preserved in each $0.01^{\circ}$ by $0.02^{\circ}$ cell (c.f. Table 1$)$.

(6) The resulting point values were interpolated to a regular grid using all the algorithms described in Sec. 3, for a sample result, see Fig. 11a.

For the SURF algorithm, the GMT default tension factor of $T=0.25$ was used. Note that the research area is situated in sub polar latitudes, around $60^{\circ} \mathrm{N}$. Therefore, an aspect ratio of $\delta \varphi=\frac{1}{2} \delta \lambda$ (where $\varphi$ is the latitude, $\lambda$ the longitude, $\delta$ the grid step increment) was used for remedying the effect of the convergence of meridians. 


\section{ACCEPTED MANUSCRIPT}

For the SPHI algorithm, a smoothing interpolation with global gradient estimation was chosen with the -Q3 option in the GMT sub-program sphinterpolate, see Renka (1997b, Sec. 2.2).

When computing a LSC solution in GEOGRID, the signal variance $C_{0}$ is automatically determined for the entire computation area, but for computational efficiency, only a limited number of (in this case 10) closest points in each quadrant are used in the prediction of each point. The second order Markov model is always used with the user specified length $X_{1 / 2}$. Importantly, in this research, a minimum limit of $0.5 \mathrm{mGal}$ was set for point standard deviation values as a measure to dampen oscillations generated by closely located points that have a small standard deviation but a larger difference in values.

For the KRIG solution, the nugget effect $c_{0}$ was set to $1 \mathrm{mGal}$.

(7) The ice and atmospheric effects were removed on the grid, resulting in a complete Bouguer anomaly grid.

(8) The terrain correction of Eq. 4 and 5 was subtracted to yield the simple Bouguer anomaly grid.

(9) The simple Bouguer correction of Eq. 2 was added to the grid, yielding the final surface gravity anomaly grid.

The effect of reducing gravity values to Bouguer anomalies is illustrated by Table 3, Fig. 8 vs. 11a and Fig. 12c vs. 12a. Note, that this reduction did not reduce the overall amplitude of the anomalies. The standard deviation of $\Delta g^{F A A}$ is $26 \mathrm{mGal}$ while that of $\Delta g^{C B A, A, I}$ is $28 \mathrm{mGal}$. 


\section{ACCEPTED MANUSCRIPT}

However, there is a significant effect in the rugged Area 1 where the standard deviation of

$\Delta g^{C B A, A, I}$ is three times smaller than that of $\Delta g^{F A A}$, see Table 3. The figures show that the reduced gravity field is much smoother and less detailed, thus also more suitable for interpolation.

\subsection{Grids computed via RTM anomalies}

Grids computed via RTM anomalies were compiled in the following way:

(1) The free-air anomaly point observations $\Delta g^{F A A}$ (Fig. 8) were first reduced by subtracting $\Delta g^{G G M}$, the second term on the right hand side of Eq. 6. $\Delta g^{G G M}$ was computed by evaluating the GO_CONS_GCF_2_DIR_R5 model up to its maximum d/o 300. For the result, see Fig. 10a.

The computation of $\Delta g^{G G M}$ at point $P$ was simplified to computing two regular grids at different (minimum and maximum) altitudes and then interpolating both in horizontal and vertical direction to specific point locations $P$ (Forsberg 1997, Sec. 2.8), thus reducing computational effort.

(2) The GGM-reduced point observations were further reduced by removing the RTM contribution (Fig. 10b) computed according to Eq. 7. The integration to compute the RTM effect was again performed over a grid of $0.001^{\circ}$ by $0.002^{\circ}$ to a distance of 15 $\mathrm{km}$ and a grid of $0.01^{\circ}$ by $0.02^{\circ}$ to a distance of $200 \mathrm{~km}$ using the GRAVSOFT subprograms TC and TCFOUR. 


\section{ACCEPTED MANUSCRIPT}

The height reference surface for the RTM reduction was computed by averaging the DTM to approximately the same resolution as the GGM. This was motivated by the fact that the GGM removal in the previous step also removes the topographic effect below the maximum d/o used and the aim of the RTM reduction is to remove the remaining topographic contribution beyond the maximum $\mathrm{d} / \mathrm{o}$ used in the previous step.

(3) The atmospheric and ice correction were applied as in Sec. 7.1.

(4) The same selection process was applied as in Sec. 7.1.

(5) The resulting point values were interpolated as in Sec. 7.1. For a sample result, see Fig. $11 b$.

(6) Again, the ice and atmospheric effects were removed on the grid, resulting in a RTM anomaly grid.

(7) The RTM contribution was restored on the grid.

(8) The GGM contribution was restored on the grid, yielding the final surface gravity anomaly grid.

The effect of reducing gravity values to RTM anomalies is illustrated by Table 3, Fig. 8 vs. $11 \mathrm{~b}$ and Fig. 12c vs. 12b. Note, how the variability of the gravity field lowers: the overall standard deviation of $\Delta g^{F A A}$ is $26 \mathrm{mGal}$ while that of $\Delta g^{R T M, A, I}$ is only $12 \mathrm{mGal}$. The variability of the field in Area 1 again reduces about three times, see Table 3. The reduced gravity signal is of short wavelength and uniform across most of the research area.

It is worth noting that the standard deviation of $\Delta g^{R T M, A, I}$ is two times smaller than that of $\Delta g^{C B A, A, I}$ in the overall statistics, but slightly larger in Area 1 statistics. This suggests that 


\section{ACCEPTED MANUSCRIPT}

RTM and Bouguer anomalies could be more suitable for gridding in low-elevation and rugged terrain areas respectively.

\subsection{Test grids}

Altogether, fourteen different free-air anomaly grids were computed, see Table 4. Grids named G1 to G4 and G5 to G8 were computed exactly as described in Sec. 7.1 and 7.2 respectively, using the corresponding interpolation method in the first column of Table 4. Grids with the suffix $\mathrm{B}$ or $\mathrm{C}$ are special cases of the above.

For instance, G3B and G7B denote LSC grids that were computed by not using a priori gravity error information from the NKG database, but a fixed value of $1 \mathrm{mGal}$ instead. This was motivated by the varying quality of the $a$ priori error estimates (see Fig. 3). For example, most terrestrial gravity observations in Norway hold a pessimistic error estimate of $5 \mathrm{mGal}$ while most error estimates of analogous data over the other participating countries have been set to represent the actual quality of the observations (typically less than $1 \mathrm{mGal}$ ) after careful analysis.

G3C and G7C denote LSC grids for the computation of which only the a priori error estimates of terrestrial points located in Norway were set to $1 \mathrm{mGal}$. Although the difference from grids $\mathrm{G} 3 \mathrm{~B}$ and $\mathrm{G} 7 \mathrm{~B}$ is numerically rather small, the $\mathrm{C}$ version grids allow to keep the error information in the other countries.

G2B represents a grid otherwise like G2 with the exception that the GGM contribution $\Delta g^{G G M}$ was computed up to d/o 240 instead of the maximum d/o 300 of the satellite-only model used. The corresponding difference of the two gravity grids and the resulting quasigeoid models 


\section{ACCEPTED MANUSCRIPT}

is rather insignificant: the standard deviation is $0.44 \mathrm{mGal}$ and $0.6 \mathrm{~mm}$ respectively. The absolute maximum deviation in the resulting quasigeoid models is $1.4 \mathrm{~cm}$.

G6B represents a grid otherwise similar to G6, except that the removal and restoration of the terrain correction $\delta g^{T}$ was omitted to illustrate its effect on the gravity field and the resulting quasigeoid model. As expected, the effect is small elsewhere, but significant in rugged terrain such as Norway. In terms of the resulting quasigeoid model, the standard deviation of differences over Norwegian territory is $1.8 \mathrm{~cm}$ and maximum deviations reach $30 \mathrm{~cm}$.

\section{Assessment of the gravity anomaly grids}

\subsection{Interpolation methods}

First, the grids were analysed to evaluate the different interpolation methods. One way to do so is to examine the differences of reduced anomaly point data and the resulting reduced grid values at the point locations, see Table 4. As an illustration, these are presented for G6, G7 and G7C in Fig. 13. The residuals of SURF (G1, G5) and KRIG (G4, G8) methods appear to be numerically quite similar to those of SPHI (G2, G6).

The SPHI method shows by far the smallest residuals for the full area and test areas (see Fig. 13a and Table 4), revealing that (with the selected parameter $T=0.25$ ) it is a rather "exact" interpolation method. SPHI does not account for the errors in point data values and in case these are large, like in the marine areas or Russian territory, the SPHI method appears to follow the point data values too rigorously. 


\section{ACCEPTED MANUSCRIPT}

The LSC method shows the largest residuals, especially over areas where the a priori standard error of gravity data is large (see Figs. 3 and 13b). Over areas of high quality gravity data and lower elevations (e.g. Area 2), the LSC residuals are larger than for other methods, but not as significantly, see Table 4. Considering that LSC accounts for observation errors and that the encountered residuals are in the same order of magnitude as the a priori error estimates, these residuals should not be interpreted as errors of the interpolation process. If data with large errors are situated close to each other, the optimal interpolation surface will be a smooth one with large residuals.

Using LSC without individual or only partially individual a priori error information (grids G3B, G7B, G3C and G7C) also gives a more "exact" interpolation of the input points, see Table 4. Thus, the choice of interpolation methods somewhat narrows down to whether the $a$ priori error estimates should be trusted.

The grids' behaviour near the especially challenging Area 1 (see Fig. 12) was further analysed by examining two profiles, one crossing a fjord (Fig. 14a) and the other crossing an area where the computed grids showed large differences (Fig. 14b). The profile plots depict grids G3, G7, G7C and, to demonstrate the violent change in the resulting grid depending on the chosen error estimate, an additional grid just like G7C except that the accuracy of gravity points in Norway was estimated to be even higher, $0.5 \mathrm{mGal}$. To visualise the input information available for grid generation, neighbouring (selected) input points together with a linear (triangulated) grid from input point values are plotted as a reference. 


\section{ACCEPTED MANUSCRIPT}

At the edge of the fjord, the SPHI grids often show an abrupt zig zag pattern while LSC generates a smoother transition. All of the gridding algorithms tested in this study overestimate the gravity field, the more so, the larger the data gap next to the steep gradient. It is a typical behaviour to minimal curvature algorithms such as SPHI, but it also affects LSC depending on the covariance function. LSC with fixed (smaller) standard deviation values is affected the least, generating the most realistic gravity anomaly field model. This profile illustrates why gravity surveys in areas of steep gravity gradient should always be planned so that the immediate neighbourhood would also be covered rather densely.

On the fjord surface, the reference linear interpolation probably shows quite a realistic gravity field as the gravity data are dense and accurate. There, all of the tested algorithms underestimate the gravity field with SPHI usually going 5 to $10 \mathrm{mGal}$ further down than the other algorithms.

In the future, gridding in such fjord areas can be improved by using bathymetric corrections which should reduce the extreme gradient currently present in the reduced gravity field.

A single point that stands out from the surrounding field (Fig. 14b), that may or may not be erroneous, is expectedly reflected most in the SPHI grid and least in the LSC grid with individual weights (as in this particular case the a priori error estimates were large and the corresponding point weights thus small). 


\section{ACCEPTED MANUSCRIPT}

It is worth noting how large in magnitude are the differences in the grids on both of the profiles, also between the LSC grids. These differences do not correspond directly to the a priori error estimates supplied.

Another aspect discussed earlier is the behaviour of different interpolation methods in data gaps that are often present in marine areas. Let us inspect the reduced gravity grids of Area 3 (Fig. 15), starting with Fig. 15b depicting the SPHI grid. Triangular patterns have formed, the most prominent one being at $55^{\circ} 5^{\prime} \mathrm{N}, 6^{\circ} 30^{\prime} \mathrm{E}$. There is at least one area around $55^{\circ} 35^{\prime} \mathrm{N}, 7^{\circ} 10^{\prime}$ E (depicted in purple) where an extreme minima is generated that most likely does not reflect the actual gravity signal. In addition, there were several other marine areas West of Norway, where the SPHI algorithm generated erratic maxima in the order of up to $100 \mathrm{mGal}(!)$. In general, there is abundance of noise around and between the survey tracks. It is clear that SPHI does not qualify for interpolating track wise (marine gravity) data.

On the plot of the SURF grid (Fig. 15a), and also the very similar KRIG grid, smaller anomaly values can be seen at the close vicinity of input gravity point tracks compared to the areas in between, thus generating unrealistic undulation between the tracks. The LSC grid (Fig. 15c) is clearly the most physically meaningful grid in Area 3, although it also suffers slightly of similar undulation, see the NE-SW track close to which the gravity values are slightly larger than in the neighbourhood.

\subsection{Gravity reduction methods}

Second, the grids were analysed and compared to evaluate the suitability of the RTM or the Bouguer anomalies for interpolation. The differences in reduced point values from the grid 


\section{ACCEPTED MANUSCRIPT}

values presented in Table 4 are very similar for both reduction schemes with neither of the methods showing significantly smaller RMS or extreme values.

Although free-air anomalies are rough and maybe not best suited for evaluation, the final free-air anomaly grids were also compared to input free-air anomalies. The only interpolation method for which either of the reduction methods shows smaller residuals, is LSC, where the grid computed via RTM anomalies shows $9 \%$ and $11 \%$ better RMS values in the overall and Area 1 statistics respectively.

The two reduction methods have different physical meaning, but the resulting surface gravity anomaly grids show a similar fit to the input data. It is difficult to prefer either of the reduction methods based on the test results obtained. A reason to prefer RTM anomalies could be their properties of shorter correlation length that are theoretically more suitable for gridding, see Sec. 6.5.

\subsection{Overall gridding quality}

Leaving aside the extreme examples represented by Area 1 and 3, in most areas, especially where sufficiently high quality data is available (e.g. Area 2), it seems clear that both of the reduction and all of the interpolation methods could in practice be considered for gravity gridding tasks. This is further supported by the GNSS/levelling evaluations of the corresponding gravimetric quasigeoid models presented in the next section.

Under this assumption of all the reduction and interpolation methods being equally plausible, the uncertainty stemming from the use of different gridding approaches is illustrated 


\section{ACCEPTED MANUSCRIPT}

by the standard deviation of the values of the different test grids in each grid cell, see Fig. 16. Thus, free-air gravity grid accuracy better than $0.5 \mathrm{mGal}$ can only be reached in flat areas with high quality gravity data such as Area 2, Denmark and Estonia, while the accuracy is limited to around $1 \mathrm{mGal}$ in areas with slightly lower quality gravity data (Latvia and Lithuania) or higher terrain such as Sweden and Finland. Due to sparse data tracks, the marine areas are affected most by the choice of gridding methods, even if the spline based grids are excluded from such an evaluation.

The research area is rather heterogeneous in terms of topography and data coverage, offering an overview of expected gridding results in varying conditions. However, in other similar computations, the results presented here can only be of general reference as the final grid is strongly dependent on the local situation -- topography, bathymetry, gravity data coverage, distribution etc.

\section{Assessment by subsequent quasigeoid models}

The main aim of the NKG project is to compute a quasigeoid model. Each gravity anomaly grid yields a preliminary quasigeoid model that is computed using Least Squares Modification of Stokes' formula with Additive Corrections (LSMSA, Sjöberg 1984; 1991; 2003). The LSMSA method is likely to be applied in the final NKG2015 quasigeoid computation (that will be reported upon in a separate publication, see also Ågren et al. 2016).

These gravimetric quasigeoid models were then compared with each other and to national GNSS/levelling datasets, i.e. to a geometric geoid determined from the difference of physical and 


\section{ACCEPTED MANUSCRIPT}

ellipsoidal heights. The physical (normal) heights are either in the national EVRS realisations with land uplift epoch 2000.0 (Nordic countries) or in the pan-European EVRS realisation European Vertical Reference Frame (EVRF) 2007 (Baltic countries), which also has the epoch 2000.0. The zero permanent tide system is used for the physical heights. The GNSS heights above the ellipsoid were first transformed into European Terrestrial Reference Frame (ETRF) 2000 with land uplift epoch 2000.0 using the NKG transformation parameters derived by Häkli et al. (2016) and then converted to the zero permanent tide system. It is important to note that the following results may also contain the errors in GNSS/levelling control points used for the quasigeoid validation.

The resulting RMS values of GNSS/levelling residuals (after mean removal) are reported in Table 5. In the NKG Area, there are all together 2538 points, out of which 51 and 23 fall in test Area 1 and 2 respectively. Again, the residuals are larger for the LSC grids, especially in the mountainous Area 1. However, the LSC associated residuals in the NKG Area result only from the algorithm generating an unrealistically smooth grid in Norway. Note that LSC yields the best fit in Area 2. Also, quasigeoid models computed from the B and C versions of LSC grids show a better fit than the original LSC with individual error estimates. There is practically no numerical difference in the two reduction methods, except that LSC grids yield a slightly better fit to quasigeoid models in conjunction with RTM anomalies rather than the Bouguer anomalies.

Unfortunately GNSS/levelling data are not available over marine areas. Therefore, in specified computations the choice of gridding methods suitable for marine areas needs to rely on 


\section{ACCEPTED MANUSCRIPT}

the gravity grid analysis above and the conclusions drawn from studying land areas with similar gravity field and data coverage characteristics.

The expected accuracy of quasigeoid models related to the used gravity gridding approach was analysed, again presuming, that all the tested gridding methods are equally plausible in many practical cases. The expected accuracy for the NKG area is illustrated by the standard deviation of quasigeoid models computed using the different gravity grids, see Fig. 17. Therefore, from the gravity data gridding point of view, it is possible to compute a $5 \mathrm{~mm}$ (quasi)geoid model over most of the Nordic-Baltic dry land. Again, the marine areas are affected most by the choice of gridding methods. If the spline based grids are excluded from such an evaluation, $1 \mathrm{~cm}$ accuracy can be expected over most of the Baltic Sea (except the Eastern part of GOF), but the situation does not improve much over remote parts of the Arctic Ocean. Thus, for the optimum outcome, the data situation and gridding approaches still need to be improved in view of the desired $5 \mathrm{~mm}$ accuracy geoid model.

\section{Conclusions}

This contribution compared and analysed methods of computing a surface gravity anomaly grid from scattered survey data. A general remove-interpolate-restore method was used, that is, the surface gravity anomalies were reduced before and restored after the interpolation process. Two concurrent reduction and four interpolation methods were studied and assessed in the extended Nordic-Baltic area. The entire work flow of gravity data processing together with the effect of some alternative processing choices was discussed. The gravity field model was reduced to 


\section{ACCEPTED MANUSCRIPT}

complete Bouguer or Residual Terrain Model (RTM) anomalies; the interpolation methods analysed include two spline-based (SURF and SPHI) and two statistical (LSC and KRIG) methods. LSC was the only method allowing points to be weighted according to individual $a$ priori error estimates. The resulting gravity grids were assessed by comparison to input data and subsequent GNSS/levelling fit to the quasigeoid model.

Overall, it is not so crucial whether the surface gravity anomaly grid is computed via RTM or Bouguer type anomalies. The numerical results are similar in reasonably flat terrain areas containing high quality observations. Due to their more homogeneous and isotropic property, in conjunction with statistical interpolation methods such as LSC, the RTM anomalies perform slightly better.

The spline-based interpolation methods SURF and SPHI generate a rather "exact" grid that closely follows the input data. So does the KRIG method, at least when using the parameters fitted for the current dataset. The result of LSC interpolation depends significantly on the quality of the a priori error estimates: if these are not trustworthy, the benefits of using LSC with individual weights become disadvantages.

It is advisable not to judge an interpolation method only according to its ability to generate a grid matching the input data as closely as possible. If the residuals between input point data and the resulting grid are within the limits of data error estimates, a smoother grid can in fact be physically more realistic and thus more appropriate. This is especially valid for marine areas where data points are often available along sparsely placed and rather inaccurate survey tracks, but the gravity field is usually quite smooth. 


\section{ACCEPTED MANUSCRIPT}

Both spline based methods, especially SPHI, are best used in areas with many observations and no data gaps. Grids computed by SPHI displayed some uncontrolled behaviour over marine areas with track wise gravity coverage, data gaps and next to steep gravity gradients. In such areas, other methods, such as LSC, should be preferred for generating a physically meaningful gravity grid.

Based on the above, it was concluded that, provided that realistic error estimates are available, gridding RTM anomalies using LSC results in the highest quality gravity field representation.

It was also demonstrated that changing the maximum d/o (within reasonable limits of 240 to 300) to which the GGM is evaluated when computing RTM anomalies, has insignificant effect on the resulting gravity field and subsequent quasigeoid models. As expected, the use of simple instead of complete Bouguer anomalies in gridding has a notable effect on the resulting quasigeoid model in areas of rugged terrain and almost no positive effect elsewhere. Over the rugged Norwegian territory, these differences had a standard deviation of $\pm 2 \mathrm{~cm}$.

The expected accuracy of quasigeoid models related to the used gravity gridding approach was analysed in view of the geodetic community now aiming at $5 \mathrm{~mm}$ accuracy in (quasi)geoid modelling. The standard deviation of quasigeoid models computed from different gravity grids confirmed that a quasigeoid model with an accuracy of $5 \mathrm{~mm}$ could be computed in most areas with terrain elevations up to $2 \mathrm{~km}$ and gravity data with an average error estimate of $1.8 \mathrm{mGal}$ available with a density of 1 points per $10 \mathrm{~km}^{2}$. However, accuracy of $5 \mathrm{~mm}$ cannot yet be reached over more rugged terrain and most marine areas. 


\section{ACCEPTED MANUSCRIPT}

The main recommendations for the NKG2015 geoid modelling project that motivated this research are the following. First, both, Bouguer type or RTM anomalies may be used for gridding. Second, in general, any of the tested interpolation methods may be used. However, the SPHI method should be avoided due to unrealistic and extreme behaviour in between the marine data tracks. Also, in Norway, where many of the a priori error estimates for contemporary terrestrial gravity data are set to be unrealistically large (i.e. 5 mGal), the usage of LSC with such individual a priori error estimates should be avoided. Attempts to provide more realistic error estimates should be encouraged.

Gravity gridding is of interest to other ongoing geodetic projects, for example the multinational GEOMED 2 (Barzaghi et al. 2016) and the EGG (Denker 2016) co-operation projects, or countries like Canada, USA, Russia or Australia that have a large area covered with inhomogeneous gravity data. Also, accurate gravity field and geoid modelling is a key feature in the realisation of the International Height Reference System (IHRS) reference stations and other datum unification tasks.

Although the gravity gridding procedure was analysed in ample detail, further work outside the scope of this study can be conducted to elaborate the analysis reported above. Other gravity reduction methods, such as isostatic reductions, could be compared to the two methods tested. All of the gravity reductions could be improved by including density and bathymetry information, undoubtedly improving the accuracy of the resulting marine geoid model. Statistical interpolation could be improved by future research in non-stationary covariance function modelling (see e.g. Darbeheshti and Featherstone 2009). The KRIG solutions could be improved 


\section{ACCEPTED MANUSCRIPT}

by including individual error estimates as it was done for the LSC method and the spline-based solutions of SURF and SPHI by tuning the tension factor according to some criterion to better fit the characteristics of the gravity field automatically in a specific area. The gravity data could benefit from automatically varying cross validation limits for gross error detection according to the field's roughness. Over the open oceans, it could be beneficial to include satellite altimetry data (in combination with terrestrial data) as these have been shown to reach accuracies of a few

mGal thanks to newer Cryosat and Sentinel satellite related improvements (Andersen and Knudsen 2016). As for the specific area of the Nordic-Baltic region, improvements in the Baltic Sea gravity grid are expected due to the FAMOS project (FAMOS Consortium 2014) collecting new ship borne gravity data.

The recommendations and methodological approaches discussed above, together with the concerns and exceptions mentioned, are applicable to other gravity gridding tasks worldwide. A resulting surface gravity anomaly grid can serve as input to numerous geoscientific tasks. Other types of gravity anomalies, for example those used in geophysical studies or concurrent geoid modelling techniques, can then be derived from the surface gravity anomaly grid.

\section{Acknowledgements}

The Nordic Geodetic Commission (NKG) is thanked for making this study possible. Besides the affiliations of the authors of this contribution, the National Land Service under the Ministry of Agriculture in Lithuania, the Danish Geodata Agency, the Geological Survey of Norway and the Estonian University of Life Sciences are explicitly acknowledged for their data contributions. 


\section{ACCEPTED MANUSCRIPT}

Some of the authors have been co-financed by a Connecting Europe Facility (CEF) project

"FAMOS (Finalising Surveys for the Baltic Motorways of the Sea) Odin" (VEU16013). The figures of this contribution have been generated using GMT (Wessel et al. 2013). Two anonymous reviewers and the editor are thanked for their constructive comments on the manuscript. 


\section{ACCEPTED MANUSCRIPT}

\section{References}

Ågren, J., 2009. Beskrivning av de nationella geoidmodellerna SWEN08_RH2000 och SWEN08_RH70 (Description of national geoid models SWEN08_RH2000 and SWEN08_RH70) (No. 2009:1), Reports in Geodesy and Geographic Information Systems. Gävle, Sweden.

Ågren, J., 2004. Regional geoid determination methods for the era of satellite gravimetry: numerical investigations using synthetic earth gravity models. KTH Royal Institute of Technology, Stockholm, Sweden.

Ågren, J., Sjöberg, L.E., 2014. Investigation of gravity data requirements for a 5 mm-quasigeoid model over Sweden, in: Gravity, Geoid and Height Systems: Proceedings of the IAG Symposium GGHS 2012, October 9 - 12, 2012, Venice, Italy, International Association of Geodesy Symposia. Springer International Publishing, pp. 143-150.

Ågren, J., Sjöberg, L.E., Kiamehr, R., 2009. The new gravimetric quasigeoid model KTH08 over Sweden. Journal of Applied Geodesy 3, 143-153. doi:10.1515/JAG.2009.015

Ågren, J., Strykowski, G., Bilker-Koivula, M., Omang, O., Märdla, S., Forsberg, R., Ellmann, A., Oja, T., Liepinš, I., Paršeliūnas, E., Kaminskis, J., Sjöberg, L., Valsson, G., 2016. The NKG2015 gravimetric geoid model for the Nordic-Baltic region, in: 1st Joint Commission 2 and IGFS Meeting International Symposium on Gravity, Geoid and Height Systems. Thessaloniki, Greece, 19-23 September. 


\section{ACCEPTED MANUSCRIPT}

Ågren, J., Strykowski, G., Bilker-Koivula, M., Omang, O., Märdla, S., Oja, T., Liepinš, I., Paršeliūnas, E., Forsberg, R., Kaminskis, J., Ellmann, A., Sjöberg, L., Valsson, V., 2015. On the development of the new Nordic gravimetric geoid model NKG2015, in: 26th IUGG General Assembly. Prague, Czech Republic, June 22 - July 2.

Andersen, O.B., 2010. The DTU10 Global Gravity field and mean sea surface - improvements in the Arctic, in: Second International Symposium of the Gravity Field of the Earth (IGFS2). Fairbanks, Alaska.

Andersen, O.B., Knudsen, P., 2016. Deriving and evaluating the DTU15 Global high resolution marine gravity field, in: 1st Joint Commission 2 and IGFS Meeting International Symposium on Gravity, Geoid and Height Systems. Thessaloniki, Greece, 19-23 September.

Bae, T.-S., Lee, J., Kwon, J.H., Hong, C.-K., 2012. Update of the precision geoid determination in Korea. Geophysical Prospecting 60, 555-571. doi:10.1111/j.1365-2478.2011.01017.x

Baptiste, J., Martelet, G., Faure, M., Beccaletto, L., Reninger, P.-A., Perrin, J., Chen, Y., 2016. Mapping of a buried basement combining aeromagnetic, gravity and petrophysical data: The substratum of southwest Paris Basin, France. Tectonophysics 683, 333-348. doi:10.1016/j.tecto.2016.05.049

Barzaghi, R., Vergos, G., Albertella, A., Carrion, D., Cazzaniga, N.E., Tziavos, I., Grigoriadis, V., Natsiopoulos, D., Bruinsma, S., Bonvalot, S., Seoane, L., Reinquin, F., LeQuentrecLalancette, M.-F., Salaun, C., Bonnefond, P., Knudsen, P., Andersen, O., Simav, M., 


\section{ACCEPTED MANUSCRIPT}

Yildiz, H., Basic, T., Varga, M., Bjelotomic, O., Gil, A.J., 2016. Gravimetric geoid model development in the Mediterranean Sea within the Geomed2 project, in: 1st Joint Commission 2 and IGFS Meeting International Symposium on Gravity, Geoid and Height Systems. Thessaloniki, Greece, 19-23 September.

Bilker-Koivula, M., 2014. Assessment of High-Resolution Global Gravity Field Models and Their Application in Quasi-geoid Modelling in Finland, in: Marti, U. (Ed.), Gravity, Geoid and Height Systems: Proceedings of the IAG Symposium GGHS 2012, October 9 12, 2012, Venice, Italy, International Association of Geodesy Symposia. Springer, pp. 51-58. doi:10.1007/978-3-319-10837-7_7

Bilker-Koivula, M., 2010. Development of the Finnish Height Conversion Surface FIN2005N00. Nordic journal of surveying and real estate research 7.

Bolkas, D., Fotopoulos, G., Braun, A., 2016. On the impact of airborne gravity data to fused gravity field models. J Geod 90, 561-571. doi:10.1007/s00190-016-0893-x

Bruinsma, S.L., Förste, C., Abrikosov, O., Marty, J.-C., Rio, M.-H., Mulet, S., Bonvalot, S., 2013. The new ESA satellite-only gravity field model via the direct approach. Geophys. Res. Lett. 40, 3607-3612. doi:10.1002/grl.50716

Cressie, N., 2015. Statistics for Spatial Data, 2 edition. ed. Wiley-Interscience, Hoboken, NJ.

Darbeheshti, N., Featherstone, W.E., 2009. Non-stationary covariance function modelling in 2D least-squares collocation. Journal of Geodesy 83, 495-508. doi:10.1007/s00190-008$0267-0$ 


\section{ACCEPTED MANUSCRIPT}

Denker, H., 2016. A new European Gravimetric (Quasi)Geoid EGG2015, in: 1st Joint Commission 2 and IGFS Meeting International Symposium on Gravity, Geoid and Height Systems. Thessaloniki, Greece, 19-23 September.

Denker, H., 2013. Regional Gravity Field Modeling: Theory and Practical Results, in: Xu, G. (Ed.), Sciences of Geodesy - II. Springer Berlin Heidelberg, pp. 185-291. doi:10.1007/978-3-642-28000-9_5

Denker, H., Barriot, J.-P., Barzaghi, R., Fairhead, D., Forsberg, R., Ihde, J., Kenyeres, A., Marti, U., Sarrailh, M., Tziavos, I.N., 2009. The Development of the European Gravimetric Geoid Model EGG07, in: Sideris, M.G. (Ed.), Observing Our Changing Earth: Proceedings of the 2007 IAG General Assembly, Perugia, Italy, July 2-13, 2007, International Association of Geodesy Symposia. Springer Berlin Heidelberg, pp. 177185. doi:10.1007/978-3-540-85426-5_21

Dermanis, A., 1984. Kriging and Collocation - A Comparison. Manuscripta Geodetica 9, 159167.

DMA, 1987. Supplement to Department of Defense World Geodetic System 1984 Technical Report: Part II - Parameters, Formulas and Graphics for the Practical Application of WGS84 (Technical Report No. 8350.2-B). Defence Mapping Agency.

Elkins, T.A., 1951. The second derivative method of gravity interpretation. Geophysics 16, 2950. doi:10.1190/1.1437648 


\section{ACCEPTED MANUSCRIPT}

Ellmann, A., 2011. Downward continuation of airborne gravity data using high resolution global geopotentail models, in: Cygas, D., Froehner, K.D. (Eds.), Selected Papers of the 8th International Conference on Environmental Engineering, Vilnius, Lithuania, 19-20, May, 2011. Vilnius Gediminas Technical University press “Technika,” Vilnius, pp. 13151320.

Ellmann, A., 2005. Two deterministic and three stochastic modifications of Stokes's formula: a case study for the Baltic countries. Journal of Geodesy 79, 11-23. doi:10.1007/s00190005-0438-1

Ellmann, A., 2002. An improved gravity anomaly grid and a geoid model for Estonia, in: Proceedings of the Estonian Academy of Sciences, Geology. pp. 199-214.

Ellmann, A., All, T., Oja, T., 2009. Towards unification of terrestrial gravity data sets in Estonia. Estonian Journal of Earth Sciences 58, 229-245. doi:10.3176/earth.2009.4.02

Ellmann, A., Oja, T., Jürgenson, H., 2011. Kosmosetehnoloogia rakendused geoidi ja gravitatsioonivälja täpsustamiseks Eesti alal (Application of space technologies to improve geoid and gravity field models over Estonia). Geodeet 41, 22-25.

Ellmann, A., Vaníček, P., 2007. UNB application of Stokes-Helmert's approach to geoid computation. Journal of Geodynamics, Potential Fields in Geostatics and Geodynamics 43, 200-213. doi:10.1016/j.jog.2006.09.019

FAMOS Consortium, 2014. FAMOS [WWW Document]. URL http://www.famosproject.eu/famos/ (accessed 9.1.16). 


\section{ACCEPTED MANUSCRIPT}

Featherstone, W.E., 2009. Only use ship-track gravity data with caution: a case-study around Australia. Australian Journal of Earth Sciences 56, 195-199. doi:10.1080/08120090802547025

Forsberg, R., 1997. Terrain effects in geoid determination, in: Sansò, F. (Ed.), Lecture Notes, International School for the Determination and Use of the Geoid. Int. Geoid Service, DICA - Polytecnico di Milano.

Forsberg, R., 1991. A New High-Resolution Geoid of the Nordic Area, in: Rapp, R.H., Sansò, F. (Eds.), Determination of the Geoid, International Association of Geodesy Symposia. Springer New York, pp. 241-250. doi:10.1007/978-1-4612-3104-2_29

Forsberg, R., 1984. A study of terrain reductions, density anomalies and geophysical inversion methods in gravity field modelling (No. 355). The Ohio State University.

Forsberg, R., Kaminskis, J., Solheim, D., 1997. Geoid of the Nordic and Baltic Region from Gravimetry and Satellite Altimetry, in: Segawa, P.D.J., Fujimoto, P.D.H., Okubo, P.D.S. (Eds.), Gravity, Geoid and Marine Geodesy, International Association of Geodesy Symposia. Springer Berlin Heidelberg, pp. 540-547. doi:10.1007/978-3-662-03482-8_72

Forsberg, R., Olesen, A.V., 2010. Airborne Gravity Field Determination, in: Xu, G. (Ed.), Sciences of Geodesy I - Advances and Future Directions. Springer Berlin Heidelberg, pp. 83-104. doi:10.1007/978-3-642-11741-1_3

Forsberg, R., Sideris, M.G., 1993. Geoid computations by the multi-band spherical FFT approach. Manuscripta Geodaetica 18, 82-90. 


\section{ACCEPTED MANUSCRIPT}

Forsberg, R., Strykowski, G., Solheim, D., 2004. NKG-2004 Geoid of the Nordic and Baltic Area, in: Proceedings on CD-ROM from the International Association of Geodesy. Presented at the Gravity, Geoid and Satellite Gravity Missions, Aug 30 - Sep 3, 2004, Porto, Portugal.

Forsberg, R., Tscherning, C.C., 2008. An overview manual for the GRAVSOFT geodetic gravity field modelling programs. Second Edition.

Förste, C., Bruinsma, S.L., Abrikosov, O., Lemoine, J.-M., Marty, J.C., Flechtner, F., Balmino, G., Barthelmes, F., Biancale, R., 2015. EIGEN-6C4 The latest combined global gravity field model including GOCE data up to degree and order 2190 of GFZ Potsdam and GRGS Toulouse [WWW Document]. GFZ Data Services. URL http://doi.org/10.5880/icgem.2015.1

Gil, A.J., Rodríguez- Caderot, G., 1998. Processing gravity data in the territory of Andalusia. Marine Geodesy 21, 81-89. doi:10.1080/01490419809388123

Golden Software LLC, 2016. Surfer [WWW Document]. URL http://www.goldensoftware.com/products/surfer (accessed 9.1.16).

Goos, J.M., Featherstone, W.E., Kirby, J.F., Holmes, S.A., 2003. Experiments with Two Different Approaches to Gridding Terrestrial Gravity Anomalies and Their Effect on Regional Geoid Computation. Survey Review 37, 92-112. doi:10.1179/sre.2003.37.288.92 


\section{ACCEPTED MANUSCRIPT}

Haagmans, R., de Min, E., Gelderen, M., 1993. Fast evaluation of convolution integrals on the sphere using 1D FFT, and a comparison with existing methods for Stokes' integral. Manuscripta Geodaetica 18, 227-241.

Hackney, R.I., Featherstone, W.E., 2003. Geodetic versus geophysical perspectives of the “gravity anomaly.” Geophys. J. Int. 154, 35-43. doi:10.1046/j.1365-246X.2003.01941.x

Häkli, P., Lidberg, M., Jivall, L., Nørbech, T., Tangen, O., Weber, M., Pihlak, P., Aleksejenko, I., Paršeliunas, E., 2016. The NKG2008 GPS campaign - final transformation results and a new common Nordic reference frame. Journal of Geodetic Science 6, 1-33. doi:10.1515/jogs-2016-0001

Heiskanen, W.A., Moritz, H., 1967. Physical Geodesy. San Francisco W. H. Freeman and Company.

Hinze, W., Aiken, C., Brozena, J., Coakley, B., Dater, D., Flanagan, G., Forsberg, R., Hildenbrand, T., Keller, G., Kellogg, J., Kucks, R., Li, X., Mainville, A., Morin, R., Pilkington, M., Plouff, D., Ravat, D., Roman, D., Urrutia-Fucugauchi, J., Véronneau, M., Webring, M., Winester, D., 2005. New standards for reducing gravity data: The North American gravity database. GEOPHYSICS 70, J25-J32. doi:10.1190/1.1988183

Hirt, C., 2013. RTM Gravity Forward-Modeling Using Topography/Bathymetry Data to Improve High-Degree Global Geopotential Models in the Coastal Zone. Marine Geodesy 36, 183202. doi:10.1080/01490419.2013.779334 


\section{ACCEPTED MANUSCRIPT}

Hirt, C., 2010. Prediction of vertical deflections from high-degree spherical harmonic synthesis and residual terrain model data. J Geod 84, 179-190. doi:10.1007/s00190-009-0354-x

Hwang, C., Hsiao, Y.-S., Shih, H.-C., Yang, M., Chen, K.-H., Forsberg, R., Olesen, A.V., 2007. Geodetic and geophysical results from a Taiwan airborne gravity survey: Data reduction and accuracy assessment. Journal of Geophysical Research: Solid Earth 112. doi:10.1029/2005JB004220

Isaaks, E.H., Srivastava, R.M., 1989. Applied Geostatistics. Oxford University Press.

Janák, J., Vaníček, P., 2005. Mean Free-Air Gravity Anomalies in the Mountains. Stud Geophys Geod 49, 31-42. doi:10.1007/s11200-005-1624-6

Jekeli, C., Yang, H.J., Kwon, J.H., 2009. Using gravity and topography-implied anomalies to assess data requirements for precise geoid computation. J Geod 83, 1193-1202. doi:10.1007/s00190-009-0337-y

Jürgenson, H., 2003. Eesti täppisgeoidi arvutus (Determination of Estonian Precision Geoid). Estonian University of Life Sciences, Tartu, Estonia.

Klitzke, P., Sippel, J., Faleide, J.I., Scheck-Wenderoth, M., 2016. A 3D gravity and thermal model for the Barents Sea and Kara Sea. Tectonophysics, Special Issue on GeoMod 2014 - Modelling in Geoscience 684, 131-147. doi:10.1016/j.tecto.2016.04.033

Korhonen, J.V., Koistinen, T., Elo, S., Säävuori, H., Kääriäinen, J., Nevanlinna, H., Aaro, S., Haller, L.Å., Skilbrei, J.R., Solheim, D., Chepik, A., Kulinich, A., Zhdanova, L., Vaher, R., All, T., Sildvee, H., 1999. Preliminary magnetic and gravity anomaly maps of the 


\section{ACCEPTED MANUSCRIPT}

Fennoscandian shield 1: 10000 000. Special Paper - Geological Survey of Finland 173180.

Krige, D.G., 1951. A statistical approach to some mine valuation and allied problems on the Witwatersrand: by D.G. Krige.

Kuhn, M., Featherstone, W.E., Kirby, J.F., 2009. Complete spherical Bouguer gravity anomalies over Australia. Australian Journal of Earth Sciences 56, 213-223. doi:10.1080/08120090802547041

Li, J., Sideris, M.G., 1997. Marine gravity and geoid determination by optimal combination of satellite altimetry and shipborne gravimetry data. Journal of Geodesy 71, 209-216. doi:10.1007/s001900050088

Lysaker, D.I., Omang, O.C.D., Pettersen, B.R., Solheim, D., 2007. Quasigeoid evaluation with improved levelled height data for Norway. Journal of Geodesy 81, 617-627. doi:10.1007/s00190-006-0129-6

Mandal, A., Gupta, S., Mohanty, W.K., Misra, S., 2015. Sub-surface structure of a cratonmobile belt interface: Evidence from geological and gravity studies across the Rengali Province-Eastern Ghats Belt boundary, eastern India. Tectonophysics, Special issue on Comparative tectonic and dynamic analysis of cratons, orogens, basins, and metallogeny: 662, 140-152. doi:10.1016/j.tecto.2015.01.016

Märdla, S., Ellmann, A., Oja, T., Jürgenson, H., 2015. Improving and Validating Gravity Data Over Ice-Covered Marine Areas, in: Rizos, C., Willis, P. (Eds.), IAG 150 Years: 


\section{ACCEPTED MANUSCRIPT}

Proceedings of the 2013 IAG Scientific Assembly, Postdam, Germany, 1-6 September, 2013, International Association of Geodesy Symposia. Springer International Publishing, pp. 263-270. doi:10.1007/1345_2015_163

Martín, A., Anquela, A.B., Padín, J., Baselga, S., 2009. Some notes and numerical comparisons on gravity anomalies interpolation. Survey Review 41, 201-215.

Martinec, Z., 1998. Boundary-Value Problems for Gravimetric Determination of a Precise Geoid, Lecture Notes in Earth Sciences. Springer-Verlag, Berlin/Heidelberg.

Morelli, C., Gantar, C., Honkaslo, T., McConnel, R.K., Tanner, T.G., Szabo, B., Uotila, U., Whalen, C.T., 1971. The International Gravity Standardisation Network (IGSN71). Bulletin Géodésique Special Publication No. 4.

Moritz, H., 2000. Geodetic Reference System 1980. Journal of Geodesy 74, 128-133. doi:10.1007/s001900050278

Moritz, H., 1980. Advanced Physical Geodesy. Wichmann.

Nahavandchi, H., Soltanpour, A., Nymes, E., 2005. A New Gravimetric Geoidal Height Model over Norway Computed by the Least-Squares Modification Parameters, in: Jekeli, P.C., Bastos, D.L., Fernandes, P.J. (Eds.), Gravity, Geoid and Space Missions: GGSM 2004, IAG International Symposium, Porto, Portugal, August 30 - September 3, 2004, International Association of Geodesy Symposia. Springer Berlin Heidelberg, pp. 191196. doi:10.1007/3-540-26932-0_33 


\section{ACCEPTED MANUSCRIPT}

Niebauer, T.M., Sasagawa, G.S., Faller, J.E., Hilt, R., Klopping, F., 1995. A new generation of absolute gravimeters. Metrologia 32, 159. doi:10.1088/0026-1394/32/3/004

Noréus, J.P., Nyborg, M.R., Hayling, K.L., 1997. The gravity anomaly field in the Gulf of Bothnia spatially characterized from satellite altimetry and in situ measurements. Journal of Applied Geophysics 37, 67-84. doi:10.1016/S0926-9851(97)00007-4

Novák, P., Vaníček, P., Martinec, Z., Véronneau, M., 2001. Effects of the spherical terrain on gravity and the geoid. Journal of Geodesy 75, 491-504. doi:10.1007/s001900100201

Omang, O.C., Tscherning, C.C., Forsberg, R., 2012. Generalizing the Harmonic Reduction Procedure in Residual Topographic Modeling, in: Sneeuw, N., Novák, P., Crespi, M., Sansò, F. (Eds.), VII Hotine-Marussi Symposium on Mathematical Geodesy, International Association of Geodesy Symposia. Springer Berlin Heidelberg, pp. 233238. doi:10.1007/978-3-642-22078-4_35

Omang, O.C.D., Forsberg, R., 2002. The northern European geoid: a case study on longwavelength geoid errors. Journal of Geodesy 76, 369-380. doi:10.1007/s00190-0020261-X

Omang, O.C.D., Forsberg, R., 2000. How to handle topography in practical geoid determination: three examples. Journal of Geodesy 74, 458-466.

Radhakrishna, M., Lasitha, S., Mukhopadhyay, M., 2008. Seismicity, gravity anomalies and lithospheric structure of the Andaman arc, NE Indian Ocean. Tectonophysics 460, $248-$ 262. doi:10.1016/j.tecto.2008.08.021 


\section{ACCEPTED MANUSCRIPT}

Renka, R.J., 1997a. Algorithm 772: STRIPACK: Delaunay Triangulation and Voronoi Diagram on the Surface of a Sphere. ACM Trans. Math. Softw. 23, 416-434. doi:10.1145/275323.275329

Renka, R.J., 1997b. Algorithm 773: SSRFPACK: Interpolation of Scattered Data on the Surface of a Sphere with a Surface Under Tension. ACM Trans. Math. Softw. 23, 435-442. doi:10.1145/275323.275330

Saleh, J., Li, X., Wang, Y.M., Roman, D.R., Smith, D.A., 2013. Error analysis of the NGS' surface gravity database. Journal of Geodesy 87, 203-221. doi:10.1007/s00190-0120589-9

Sansò, F., Sideris, M.G. (Eds.), 2013. Geoid Determination, Lecture Notes in Earth System Sciences. Springer Berlin Heidelberg, Berlin, Heidelberg.

Sjöberg, L.E., 2003. A computational scheme to model the geoid by the modified Stokes formula without gravity reductions. Journal of Geodesy 77, 423-432. doi:10.1007/s00190-0030338-1

Sjöberg, L.E., 2000. Topographic effects by the Stokes-Helmert method of geoid and quasigeoid determinations. Journal of Geodesy 74, 255-268. doi:10.1007/s001900050284

Sjöberg, L.E., 1991. Refined Least Squares Modification of Stokes formula. Manuscripta Geodaetica 16, 367-375. 


\section{ACCEPTED MANUSCRIPT}

Sjöberg, L.E., 1984. Least squares modification of Stokes' and Vening Meinesz' formulas by accounting for truncation and potential coefficient errors. Manuscripta Geodaetica 9, $209-229$.

Smith, W.H.F., Wessel, P., 1990. Gridding with continuous curvature splines in tension. Geophysics 55, 293-305. doi:10.1190/1.1442837

Stokes, G.G., 1849. On the variation of gravity at the surface of the Earth. Trans. Cambridge Philos. Soc. VIIII, pp. 672-695.

Sünkel, H., 1986. Global topographic-isostatic models, in: Sünkel, H. (Ed.), Mathematical and Numerical Techniques in Physical Geodesy, Lecture Notes in Earth Sciences. Springer Berlin Heidelberg, pp. 417-462. doi:10.1007/BFb0010137

Tscherning, C.C., 1985. Local Approximation of the Gravity Potential by Least Squares Collocation, in: Schwarz, K.P. (Ed.), Proceedings of the International Summer School on Local Gravity Field Approximation in Beijing, China, Aug. 21 - Sept. 4 1984. University of Calgary, Calgary, Canada, pp. 277-362.

Tscherning, C.C., Forsberg, R., 1986. Geoid determination in the Nordic countries from gravity and height data, in: Bolletino Di Geodesia E Scienze Affini. Presented at the International Symposium on the Definition od the Geoid, Florence, Italy, pp. 21-43.

Tscherning, C.C., Rubek, F., Forsberg, R., 1998. Combining Airborne and Ground Gravity Using Collocation, in: Forsberg, P.D.R., Feissel, P.D.M., Dietrich, P.D.R. (Eds.), Geodesy on the Move - Gravity, Geoid, Geodynamics and Antarctica: Proceedings of 


\section{ACCEPTED MANUSCRIPT}

IAG Scientific Assembly, Rio de Janeiro, Brazil, September 3-9, 1997, International Association of Geodesy Symposia. Springer Berlin Heidelberg, pp. 18-23. doi:10.1007/978-3-642-72245-5_3

Vaníček, P., Novák, P., Martinec, Z., 2001. Geoid, topography, and the Bouguer plate or shell. Journal of Geodesy 75, 210-215. doi:10.1007/s001900100165

Vaníček, P., Sjöberg, L.E., 1991. Reformulation of Stokes's theory for higher than seconddegree reference field and modification of integration kernels. J. Geophys. Res. 96, 6529-6539. doi:10.1029/90JB02782

Vaníček, P., Tenzer, R., Sjöberg, L.E., Martinec, Z., Featherstone, W.E., 2004. New views of the spherical Bouguer gravity anomaly. Geophysical Journal International 159, 460-472. doi:10.1111/j.1365-246X.2004.02435.x

Vergos, G.S., Tziavos, I.N., Andritsanos, V.D., 2005. Gravity Data Base Generation and Geoid Model Estimation Using Heterogeneous Data, in: Gravity, Geoid and Space Missions. Springer, Berlin, Heidelberg, pp. 155-160. doi:10.1007/3-540-26932-0_27

Vermeer, M., 1994. A Fast Delivery GPS-Gravimetric Geoid for Estonia (No. 94:1), Reports of the Finnish Geodetic Institute. Finnish Geodetic Institute, Masala, Finland.

Véronneau, M., 2013. The Helmert Gravity Grid Used for CGG2010. Geodetic Survey Division, Natural Resources Canada, Ottawa, Canada (via pers. comm., 28.04.2016). 


\section{ACCEPTED MANUSCRIPT}

Wang, Y.M., Saleh, J., Li, X., Roman, D.R., 2012. The US Gravimetric Geoid of 2009 (USGG2009): model development and evaluation. J Geod 86, 165-180. doi:10.1007/s00190-011-0506-7

Wessel, P., Smith, W.H.F., Scharroo, R., Luis, J., Wobbe, F., 2013. Generic Mapping Tools:

Improved Version Released. Eos Trans. AGU 94, 409-410. doi:10.1002/2013EO450001 


\section{ACCEPTED MANUSCRIPT}

Table 1. Characteristics of the research and test area data

\begin{tabular}{|c|c|c|c|c|c|c|}
\hline & & Full area & NKG area $^{\mathrm{a}}$ & Area 1 & Area 2 & Area 3 \\
\hline No. of points & & 512772 & 172406 & 4509 & 8043 & 1819 \\
\hline$\left({\text { after selection })^{b}}^{b}\right.$ & & 421108 & 141418 & 1609 & 5928 & 1518 \\
\hline 1 point per no. of $\mathrm{km}^{2}$ & & 11.9 & 8.1 & 2.7 & 1.5 & 6.7 \\
\hline (after selection) & & 14.4 & 9.8 & 7.5 & 2.0 & 8.0 \\
\hline \multirow[t]{4}{*}{ 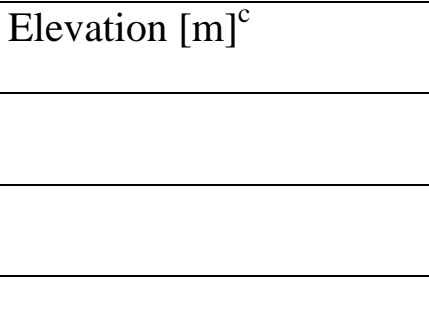 } & Mean & 107 & 304 & 882 & 68 & 0 \\
\hline & StDev & 196 & 305 & 481 & 23 & 0 \\
\hline & Min & 0 & 0 & 0 & 0 & 0 \\
\hline & Max & 2419 & 2419 & 1977 & 146 & 0 \\
\hline \multirow[t]{4}{*}{ Free-air anomaly [mGal] } & Mean & -0.48 & 0.97 & -61.84 & -12.92 & 5.71 \\
\hline & StDev & 26.41 & 28.07 & 61.24 & 9.80 & 11.53 \\
\hline & Min & -307.79 & -307.79 & -117.70 & -45.52 & -19.10 \\
\hline & Max & 210.46 & 210.46 & 145.59 & 18.18 & 35.91 \\
\hline \multirow[t]{2}{*}{ (after selection) } & Mean & -0.35 & 1.35 & -16.62 & -12.70 & 5.40 \\
\hline & StDev & 24.65 & 27.48 & 75.33 & 9.90 & 10.97 \\
\hline A priori gravity & Mean & 2.32 & 1.83 & 2.01 & 0.34 & 3.76 \\
\hline \multirow[t]{3}{*}{ error estimate [mGal] } & StDev & 1.86 & 2.07 & 1.78 & 0.11 & 2.06 \\
\hline & Min & 0.10 & 0.10 & 0.20 & 0.10 & 2.00 \\
\hline & Max & 7.00 & 5.00 & 5.00 & 0.80 & 7.00 \\
\hline \multirow[t]{2}{*}{ (after selection) } & Mean & 2.22 & 1.63 & 3.09 & 0.32 & 3.81 \\
\hline & StDev & 1.84 & 1.99 & 2.09 & 0.12 & 2.10 \\
\hline
\end{tabular}

${ }^{a}$ dry land and inland water territory of the participating Nordic-Baltic countries 


\section{ACCEPTED MANUSCRIPT}

${ }^{\mathrm{b}}$ after preserving a single point with the lowest a priori error estimate in each $0.01^{\circ}$ by $0.02^{\circ}$ grid cell

${ }^{c}$ topographic elevation statistics are given from the $0.001^{\circ}$ by $0.002^{\circ} \mathrm{DTM}$ 


\section{ACCEPTED MANUSCRIPT}

Table 2. Estimated correlation lengths of gravity anomalies*

\begin{tabular}{|l|c|c|c|}
\hline Grid & Area & $X_{1 / 2}\left[^{\circ}\right]$ & $\approx X_{1 / 2}[\mathrm{~km}]$ \\
\hline \multirow{4}{*}{$\Delta g^{C B A, A, I}$} & Full area & 0.65 & 71.5 \\
\cline { 2 - 4 } & Area 1 & 0.63 & 69.3 \\
\cline { 2 - 4 } & Area 2 & 0.23 & 25.3 \\
\cline { 2 - 4 }$\Delta g^{\text {RTMA,A,I }}$ & Area 3 & 0.49 & 53.9 \\
\hline \multirow{3}{*}{} & Full area & 0.17 & 18.7 \\
\cline { 2 - 4 } & Area 1 & 0.11 & 12.1 \\
\cline { 2 - 4 } & Area 2 & 0.21 & 23.1 \\
\cline { 2 - 4 } & Area 3 & 0.21 & 23.1 \\
\hline
\end{tabular}

*Explanation of the symbols used in this and the following tables can be found in the text 


\section{ACCEPTED MANUSCRIPT}

Table 3. Statistics of the NKG gravity anomaly points

\begin{tabular}{|c|c|c|c|c|c|c|c|c|}
\hline Quantity & Mean & StDev & Min & Max & Mean & StDev & Min & Max \\
\hline & \multicolumn{4}{|c|}{ Full area $^{\mathrm{a}}$} & \multicolumn{4}{|c|}{ Area 1} \\
\hline$\Delta g^{F A A}$ & -0.48 & 26.41 & -307.79 & 210.46 & -61.84 & 61.24 & -117.70 & 145.59 \\
\hline$\Delta g^{S B A}$ & -9.91 & 29.03 & -307.79 & 174.59 & -85.54 & 19.40 & -117.70 & -25.91 \\
\hline$\Delta g^{C B A}$ & -9.29 & 28.06 & -255.31 & 176.50 & -72.68 & 20.44 & -108.77 & -23.13 \\
\hline$\Delta g^{C B A, A, I}$ & -8.44 & 28.07 & -254.46 & 177.34 & -71.97 & 20.41 & -108.01 & -22.43 \\
\hline $\begin{array}{l}\Delta g^{C B A, A, I} \\
(\text { selected) }\end{array}$ & -8.96 & 27.13 & -254.46 & 177.34 & -61.04 & 18.97 & -107.80 & -22.47 \\
\hline$\Delta g^{F A A}-\Delta g^{G G M}$ & -3.68 & 20.95 & -342.93 & 177.49 & -109.44 & 59.95 & -181.43 & 94.03 \\
\hline$\Delta g^{R T M A}$ & -1.28 & 13.15 & -242.55 & 194.26 & -31.07 & 24.26 & -79.26 & 30.82 \\
\hline$\Delta g^{R T M A, A, I}$ & -0.42 & 13.15 & -241.70 & 195.10 & -30.36 & 24.23 & -78.51 & 32.23 \\
\hline $\begin{array}{l}\Delta g^{R T M A, A, I} \\
\text { (selected) }\end{array}$ & 0.21 & 12.27 & -241.70 & 195.10 & -15.98 & 21.64 & -78.51 & 31.23 \\
\hline
\end{tabular}

ancluding the EIGEN-6C4 GGM based fill-in on the edges, 524274 points

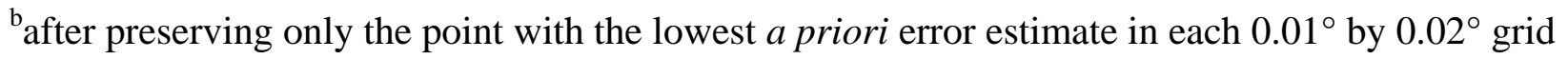
cell 


\section{ACCEPTED MANUSCRIPT}

Table 4. Reduced gravity anomalies minus interpolated values from the reduced grid, units in mGal

\begin{tabular}{|c|c|c|c|c|c|c|c|c|c|c|}
\hline \multirow[t]{2}{*}{ Interpolation method } & Grid & Mean & RMS & Min & Max & Grid & Mean & RMS & $\operatorname{Max}$ & \\
\hline & \multicolumn{5}{|c|}{$\Delta g^{C B A, A, I}$} & \multicolumn{5}{|c|}{$\Delta g^{R T M, A, I}$} \\
\hline \multicolumn{11}{|c|}{ Full area } \\
\hline SURF & G1 & -0.0035 & 0.8667 & -121.74 & 81.87 & G5 & -0.0034 & 0.8670 & -121.71 & 82.31 \\
\hline SPHI & G2 & -0.0062 & 0.5649 & -71.60 & 82.47 & G6 & -0.0063 & 0.5667 & -71.59 & 82.46 \\
\hline$\overline{L S C}$ & G3 & -0.0052 & 2.5168 & \begin{tabular}{|l}
-141.87 \\
\end{tabular} & 137.37 & G7 & 0.0260 & 2.0091 & -164.22 & 236.20 \\
\hline KRIG & G4 & -0.0029 & 0.9108 & -127.91 & 120.11 & G8 & -0.0031 & 0.8873 & -118.20 & 111.26 \\
\hline SPHI (no $\delta g^{T}$ ) & G2B & -0.0050 & 0.6737 & -136.18 & 80.55 & & & & & \\
\hline SPHI (GGM d/o 240) & & & & & & G6B & -0.0064 & 0.5641 & -71.59 & 82.47 \\
\hline $\begin{array}{l}\text { LSC (all } 1 \mathrm{mGal} \text { ) } \\
\end{array}$ & G3B & -0.0129 & 1.7532 & -228.46 & 176.31 & G7B & -0.0030 & 1.2008 & -186.71 & 155.08 \\
\hline LSC (Norw. $1 \mathrm{mGal}$ ) & G3C & -0.0404 & 2.1944 & -227.25 & 176.31 & G7C & 0.0042 & 1.5158 & -186.44 & 155.08 \\
\hline \multicolumn{11}{|c|}{ Area 1 -- Sognefjord area } \\
\hline SURF & G1 & -0.0747 & 2.5996 & -20.72 & 21.76 & G5 & -0.0721 & 2.6112 & -20.79 & 21.90 \\
\hline SPHI & G2 & -0.3660 & 1.7543 & -10.48 & 27.63 & G6 & -0.3695 & 1.7577 & -10.46 & 27.66 \\
\hline$\overline{\mathrm{LSC}}$ & G3 & 0.0430 & 6.2978 & -25.22 & 39.69 & G7 & 0.5041 & 5.3594 & -21.33 & 40.51 \\
\hline KRIG & G4 & -0.1750 & 2.8376 & -10.78 & 29.36 & G8 & -0.2068 & 2.6996 & -11.86 & 28.20 \\
\hline LSC (Norw. $1 \mathrm{mGal}$ ) & G3C & -0.5782 & 5.9242 & -22.33 & 28.30 & G7C & -0.2090 & 3.8518 & -19.18 & 22.66 \\
\hline \multicolumn{11}{|c|}{ Area 2 -- central Estonia } \\
\hline $\begin{array}{l}\text { SURF } \\
\end{array}$ & G1 & 0.0036 & 0.2073 & -0.93 & 1.76 & G5 & 0.0046 & 0.2078 & -0.95 & 1.80 \\
\hline SPHI & G2 & -0.0011 & 0.1335 & -0.71 & 0.87 & G6 & -0.0008 & 0.1336 & -0.71 & 0.87 \\
\hline
\end{tabular}




\section{ACCEPTED MANUSCRIPT}

\begin{tabular}{|l|l|r|r|r|r|l|r|r|r|r|}
\hline LSC & G3 & 0.0006 & 0.3425 & -1.94 & 2.01 & G7 & -0.0007 & 0.2007 & -1.26 & 1.10 \\
\hline KRIG & G4 & -0.0015 & 0.1983 & -1.31 & 1.10 & G8 & -0.0008 & 0.1916 & -1.24 & 1.04 \\
\hline \multicolumn{7}{|c|}{ Area 3 -- West of Denmark } \\
\hline SURF & G1 & 0.0252 & 0.9318 & -6.03 & 6.26 & G5 & 0.0236 & 0.9311 & -6.02 & 6.28 \\
\hline SPHI & G2 & 0.5608 & 0.5614 & -3.37 & 4.01 & G6 & 0.5606 & 0.5613 & -3.37 & 4.01 \\
\hline LSC & G3 & -0.4540 & 2.9997 & -10.60 & 7.81 & G7 & 0.2697 & 1.7776 & -10.75 & 7.71 \\
\hline KRIG & G4 & 0.0153 & 0.8634 & -5.37 & 3.70 & G8 & 0.0088 & 0.8530 & -5.16 & 3.55 \\
\hline
\end{tabular}




\section{ACCEPTED MANUSCRIPT}

Table 5. RMS values of the quasigeoid differences from GNSS/levelling points after mean removal

\begin{tabular}{|c|c|c|c|c|c|c|c|c|}
\hline & \multicolumn{4}{|c|}{ Quasigeoid via $\Delta g^{C B A, A, I}[\mathrm{~cm}]$} & \multicolumn{4}{|c|}{ Quasigeoid via $\Delta g^{R T M A, A, I}[\mathrm{~cm}]$} \\
\hline Interpolation & Grid & NKG area & Area 1 & Area2 & Grid & NKG area & Area 1 & Area 2 \\
\hline SURF & G1 & 2.92 & 4.94 & 2.04 & G5 & 2.92 & 4.94 & 2.08 \\
\hline SPHI & G2 & 2.85 & 3.80 & 1.96 & G6 & 2.85 & 3.82 & 1.96 \\
\hline LSC & G3 & 3.36 & 5.58 & 1.91 & G7 & 3.16 & 5.37 & 1.94 \\
\hline KRIG & G4 & 2.90 & 4.93 & 1.97 & G8 & 2.90 & 4.80 & 1.99 \\
\hline SPHI (no $\delta g^{T}$ ) & G2B & 3.05 & 5.28 & 1.97 & & & & \\
\hline $\begin{array}{l}\text { SPHI (GGM d/o } \\
240)\end{array}$ & & & & & G6B & 2.85 & 3.98 & 1.95 \\
\hline LSC (all 1mGal) & G3B & 2.96 & 5.64 & 1.97 & G7B & 2.89 & 4.66 & 1.98 \\
\hline $\begin{array}{l}\text { LSC (Norw. } 1 \\
\text { mGal) }\end{array}$ & G3C & 3.00 & 5.88 & \begin{tabular}{|l}
1.89 \\
\end{tabular} & G7C & 2.96 & 5.64 & 1.97 \\
\hline
\end{tabular}




\section{ACCEPTED MANUSCRIPT}

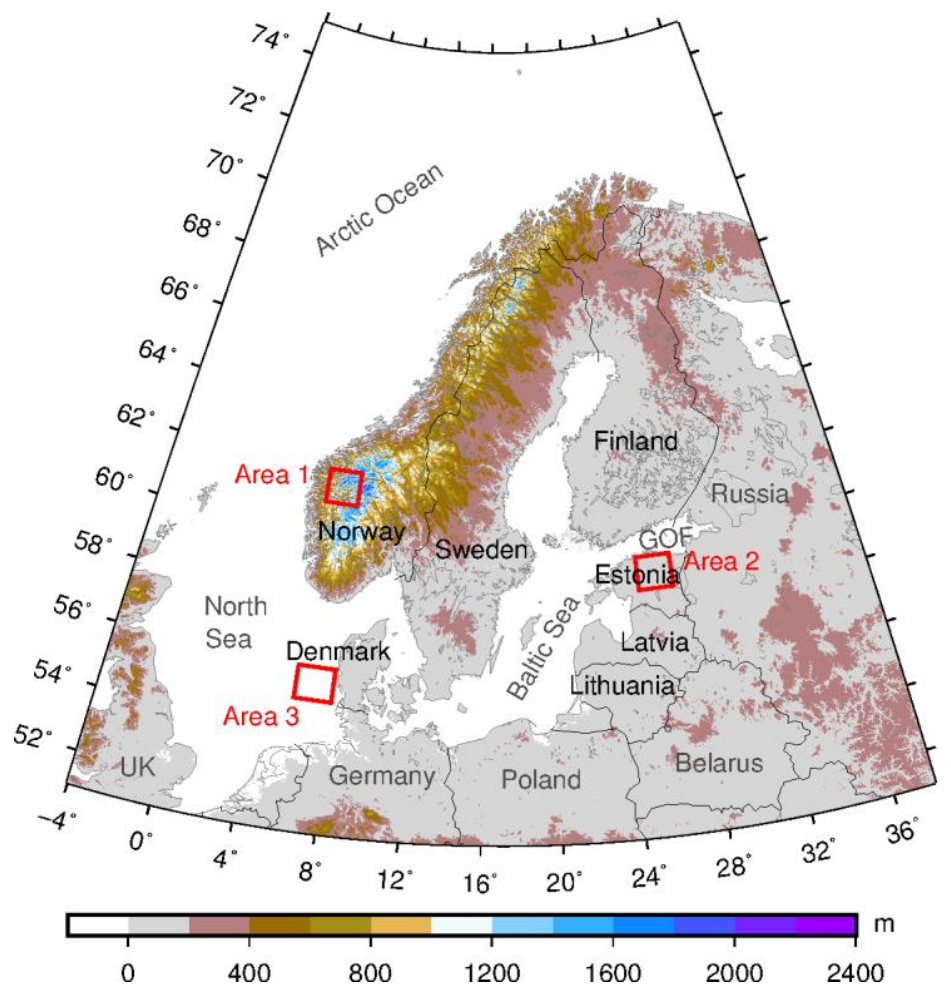

Figure 1. Terrain elevations of the NKG data area 


\section{ACCEPTED MANUSCRIPT}

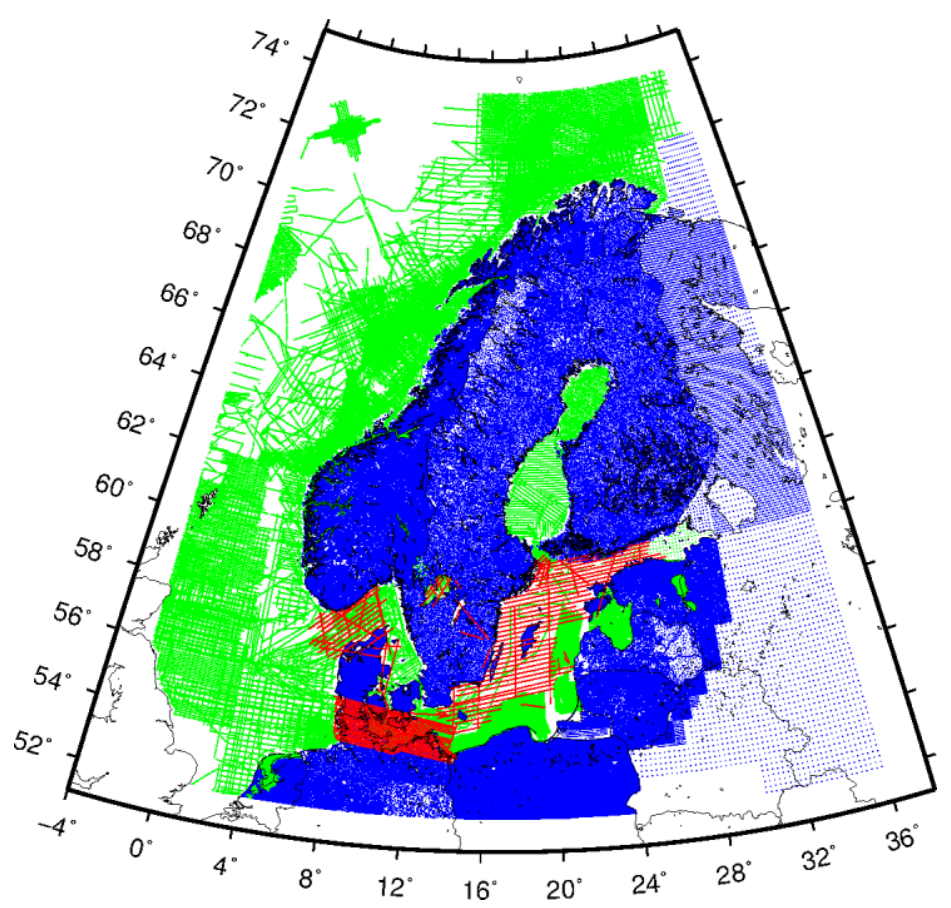

Figure 2. Distribution of the NKG gravity point data (blue - terrestrial, green - marine or sea bottom, red - airborne) 


\section{ACCEPTED MANUSCRIPT}

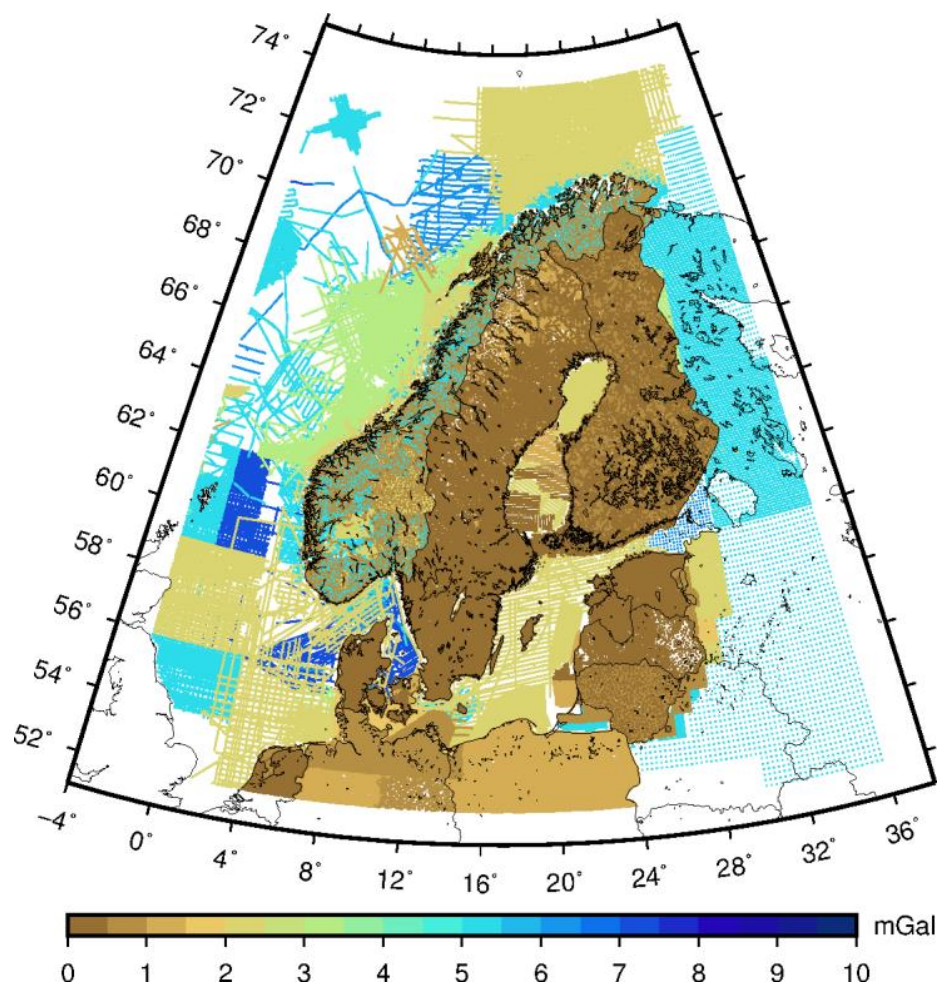

Figure 3. A priori error estimates of the NKG gravity point data 


\section{ACCEPTED MANUSCRIPT}

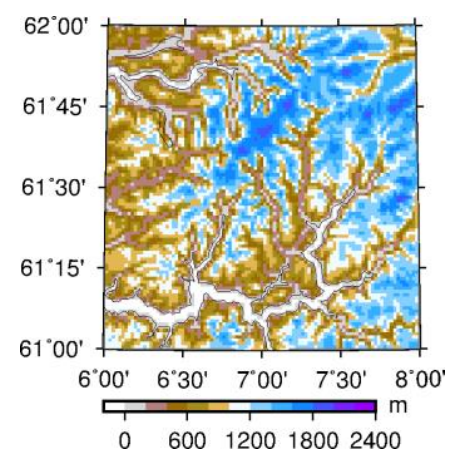

(a) Area 1 - Sognefjord area

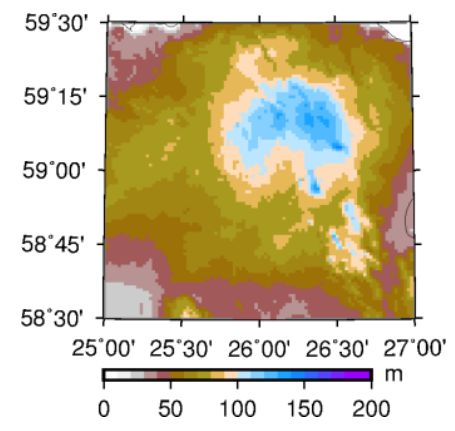

(b) Area 2 - central Estonia

Figure 4. Terrain elevations in the test areas (note the different colour scales) 


\section{ACCEPTED MANUSCRIPT}

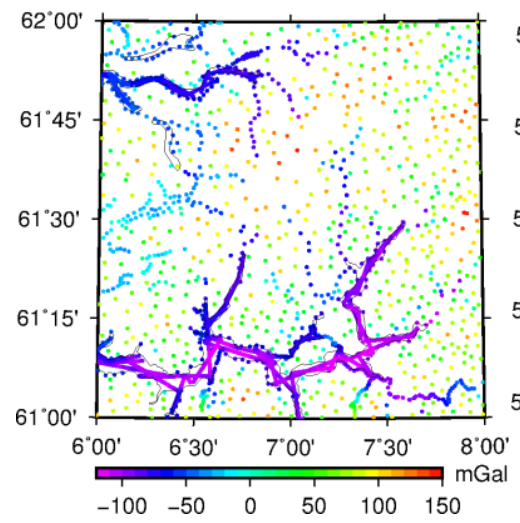

(a) Area 1 - Sognefjord area

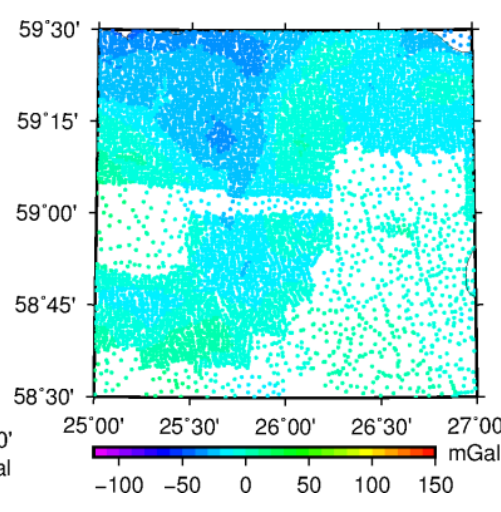

(b) Area 2 - central Estonia

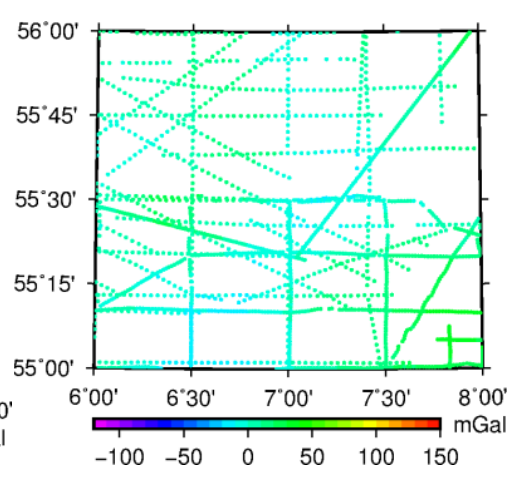

(c) Area 3 - West of

Denmark

Figure 5. Free-air gravity anomaly point data available in the test areas 


\section{ACCEPTED MANUSCRIPT}
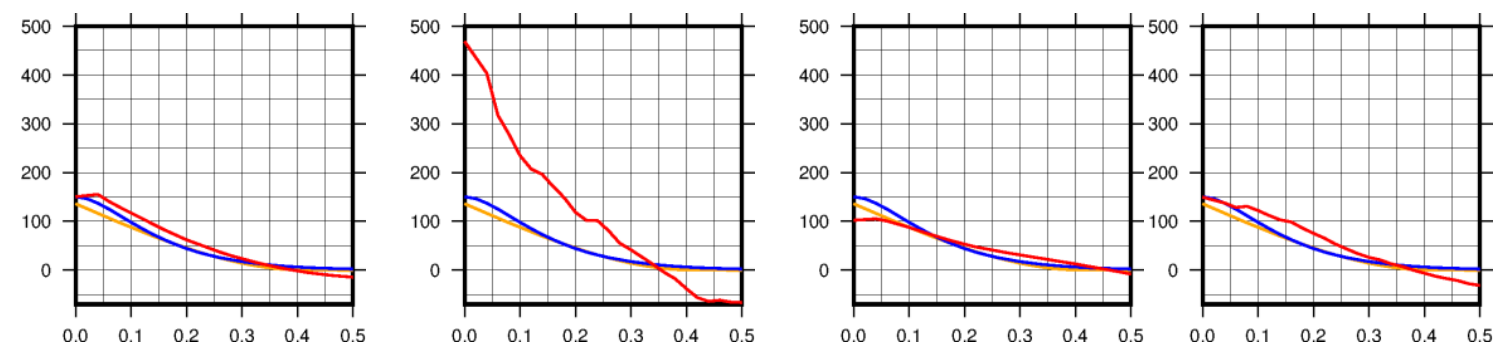

(a) Full area

(b) Area 1

(c) Area 2

(d) Area 3
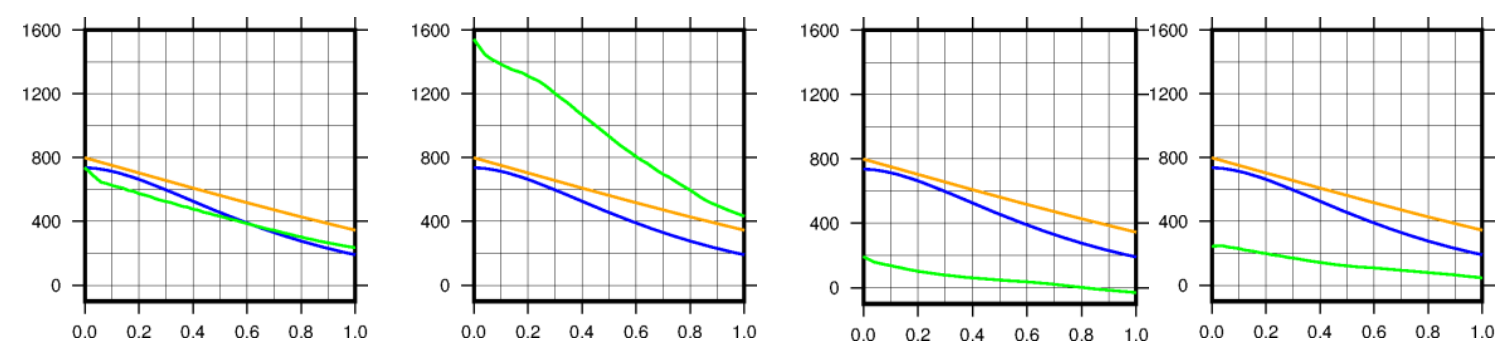

(e) Full area

(f) Area 1

(g) Area 2

(h) Area 3

Figure 6. Covariance functions for the RTM (top row) and the Bouguer (bottom row) anomalies*

*The red or green lines depict the empirical covariance function, blue line the second order Markov and orange line the spherical model. Spherical distance $\left[^{\circ}\right]$ and variance $\left[\mathrm{mGal}^{2}\right]$ are represented on the horizontal and vertical axis respectively. 


\section{ACCEPTED MANUSCRIPT}
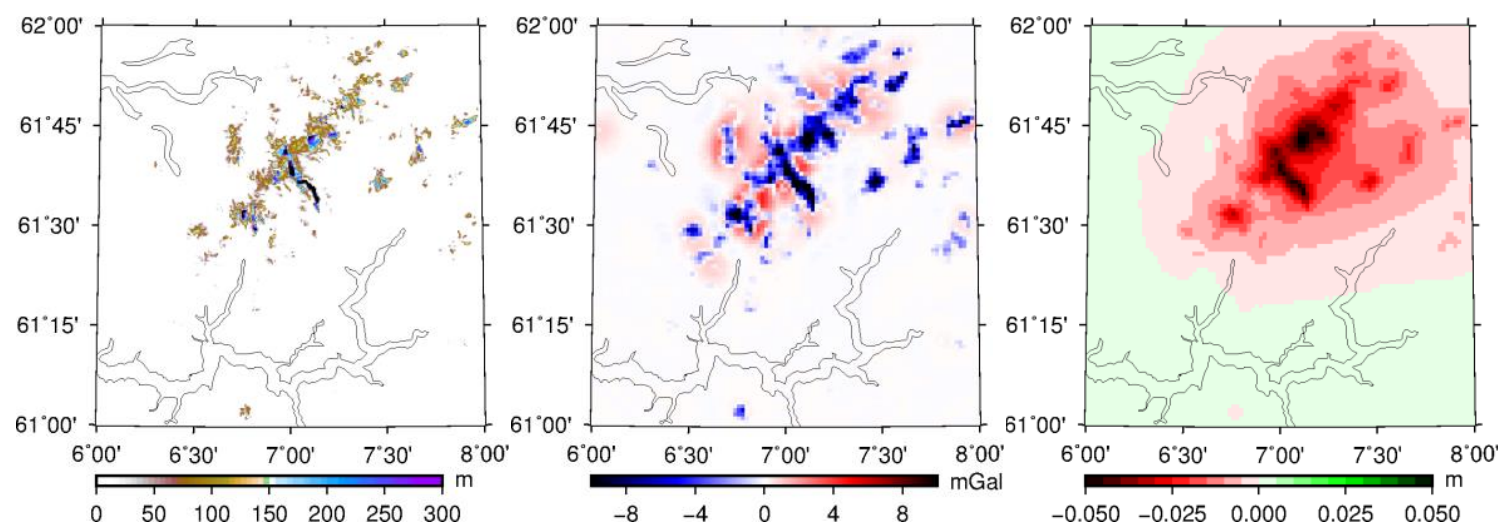

(a) Ice thickness

(b) Effect on the gravity field (c) Effect on the quasigeoid

Figure 7. Ice thickness related effects in Area 1 


\section{ACCEPTED MANUSCRIPT}

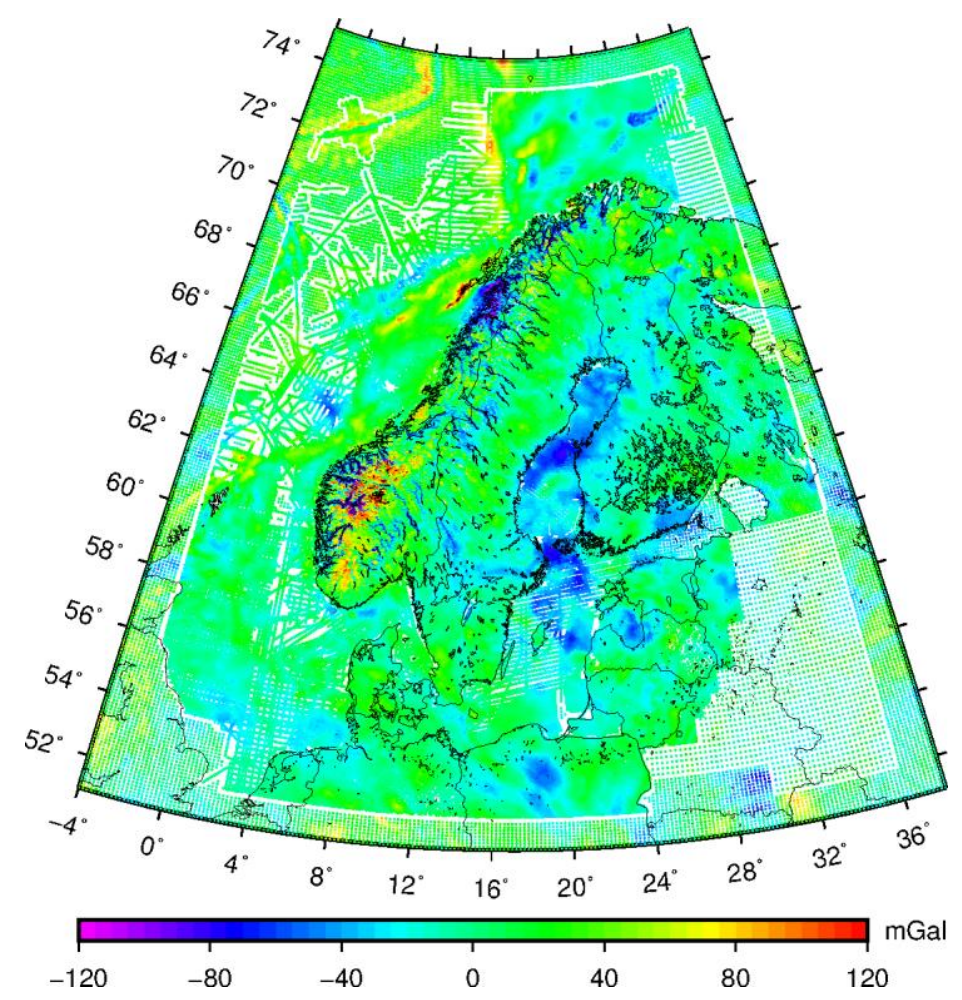

Figure 8. Free-air anomaly $\Delta g^{F A A}$ data points 


\section{ACCEPTED MANUSCRIPT}

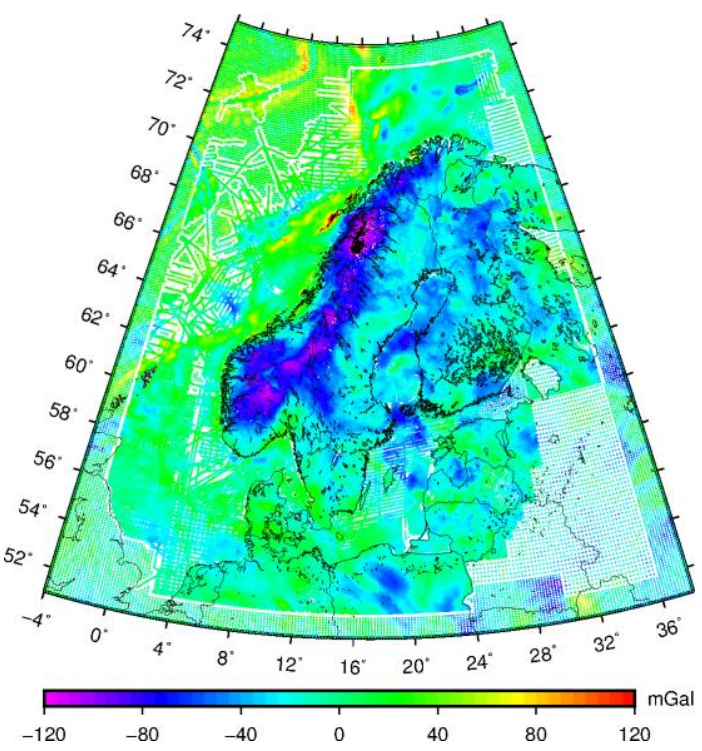

(a) Simple Bouguer anomalies $\Delta g^{S B A}$

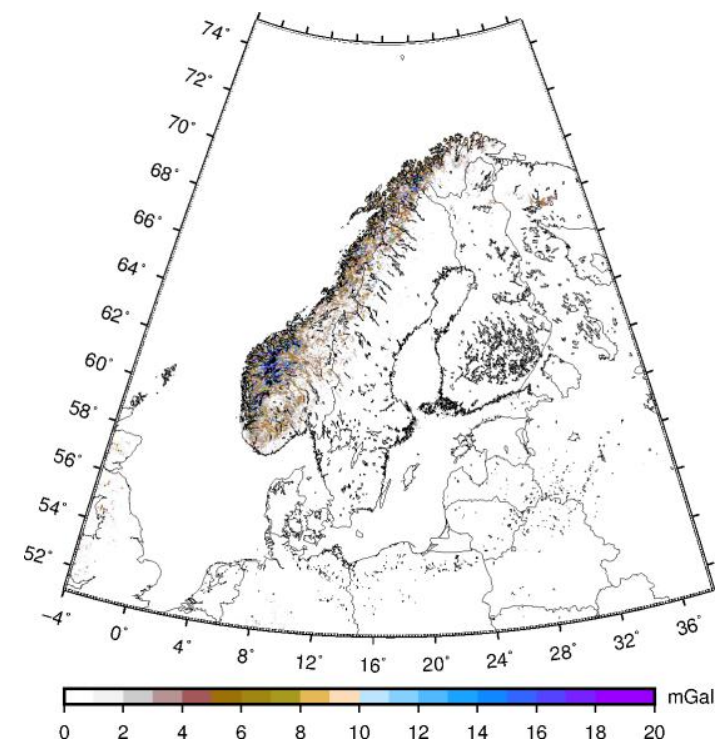

(b) Terrain corrections $\delta g^{T}$

Figure 9. The Bouguer reduction 


\section{ACCEPTED MANUSCRIPT}

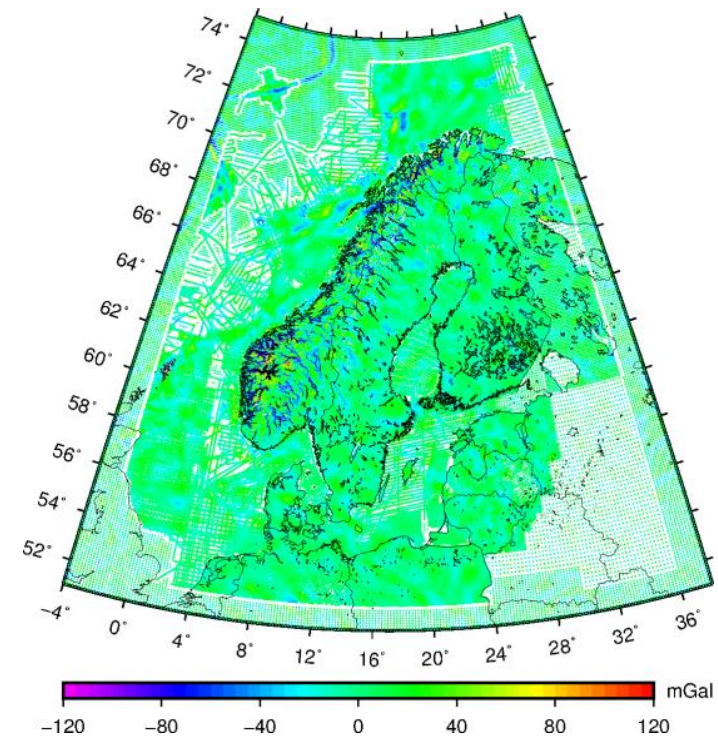

(a) Difference $\Delta g^{F A A}-\Delta g^{G G M}$

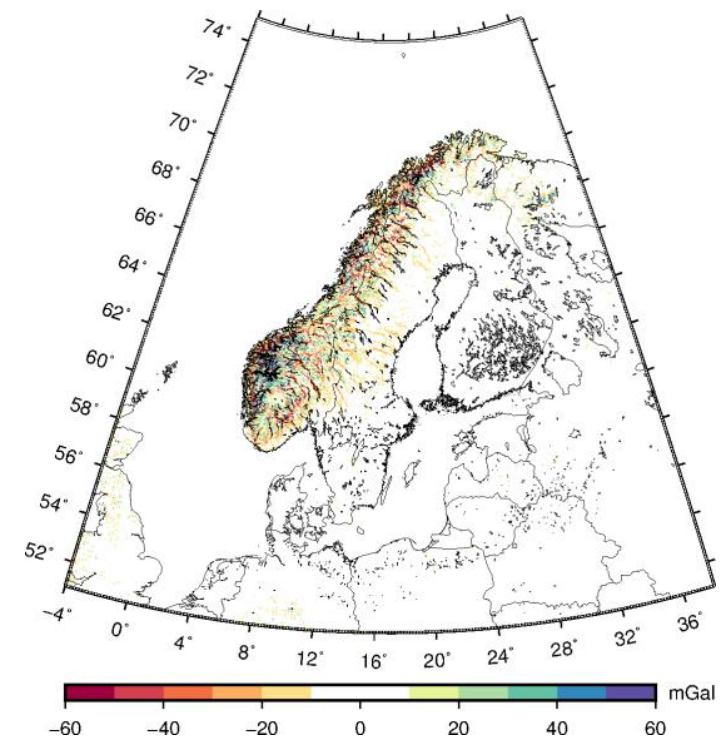

(b) RTM effect $\delta g^{R T M}$

Figure 10. The RTM reduction 


\section{ACCEPTED MANUSCRIPT}

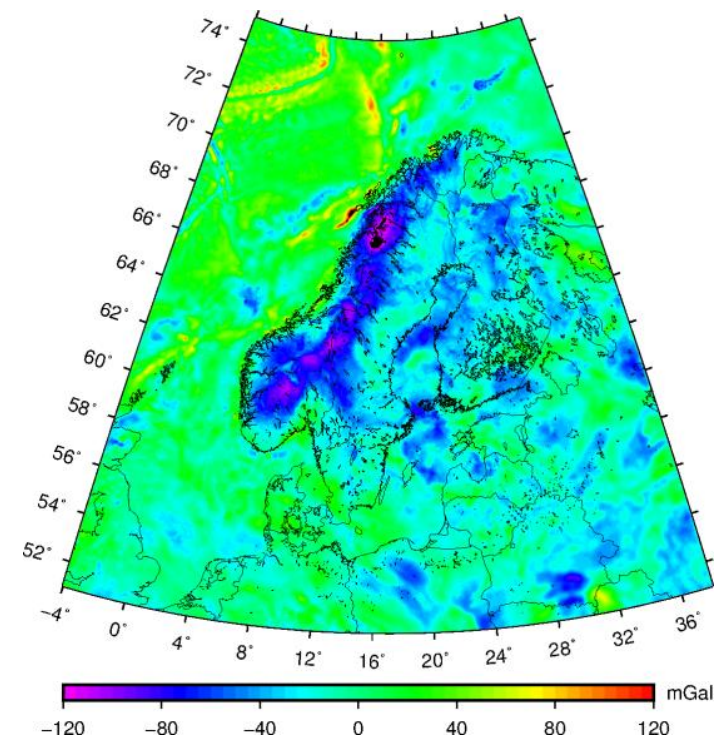

(a) $\Delta g^{C B A, A, I} \operatorname{grid}(\mathrm{G} 3)$

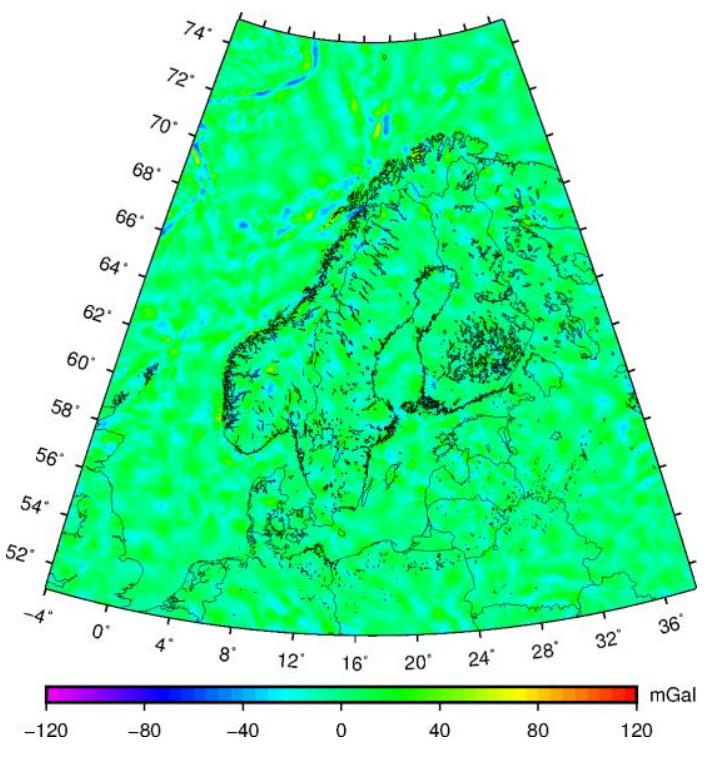

(b) $\Delta g^{R T M A, A, I} \operatorname{grid}(\mathrm{G} 7 \mathrm{C})$

Figure 11. Reduced gravity anomaly grids (interpolated by LSC) 


\section{ACCEPTED MANUSCRIPT}
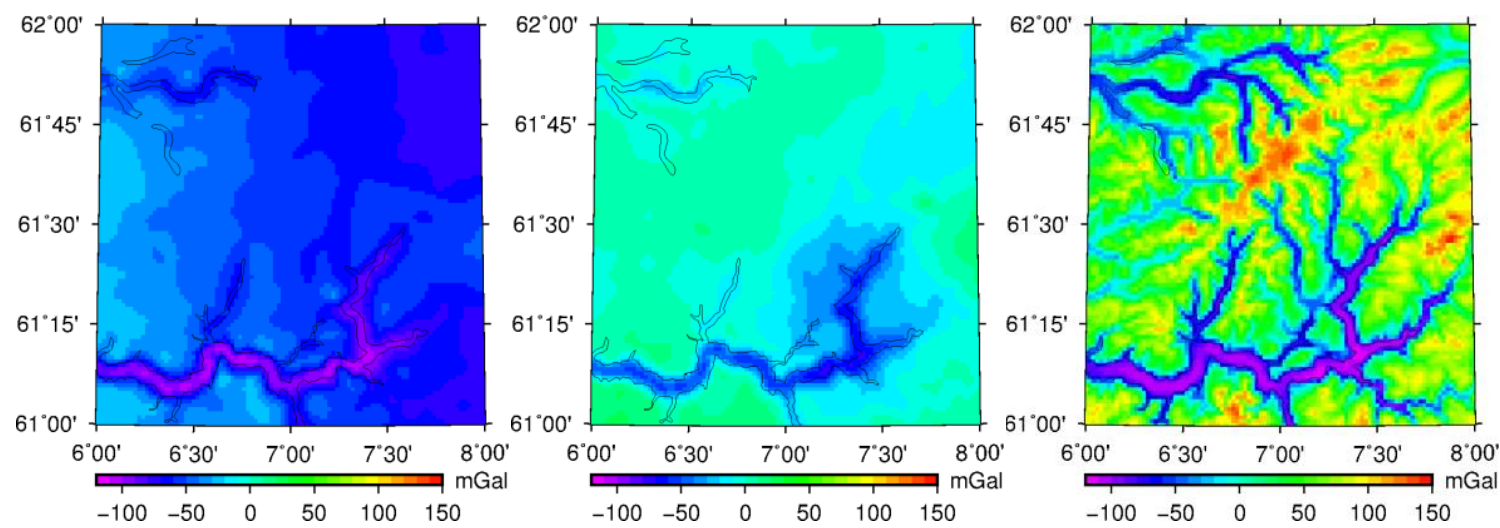
(a) $\Delta g^{C B A, A, I} \operatorname{grid}(\mathrm{G} 3)$
(b) $\Delta g^{R T M A, A, I} \operatorname{grid}(\mathrm{G} 7 \mathrm{C})$
(c) $\Delta g^{F A A}$ grid (G7C)

Figure 12. Reduced $(\mathrm{a}, \mathrm{b})$ and restored (c) LSC-derived gravity anomaly grids in Area 1 


\section{ACCEPTED MANUSCRIPT}

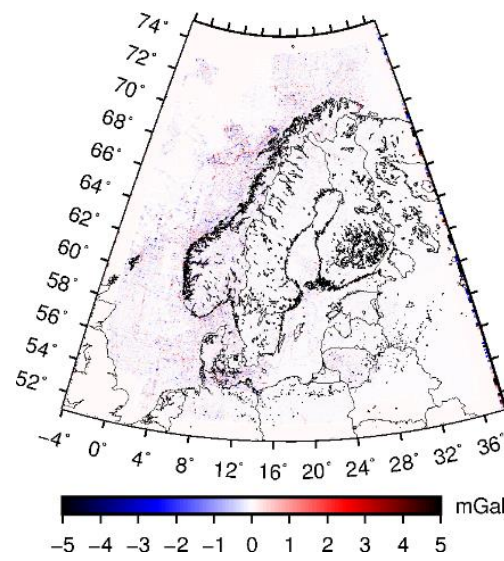

(a) G6 $-\Delta g^{R T M A, A, I}$ grid

interpolated by SPHI

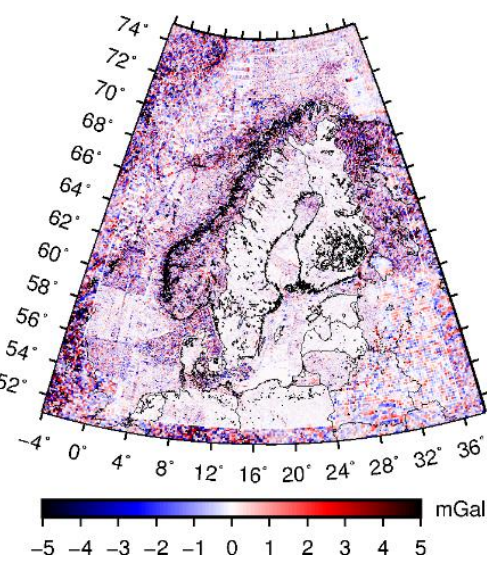

(b) G7 $-\Delta g^{R T M A, A, I}$ grid

interpolated by LSC

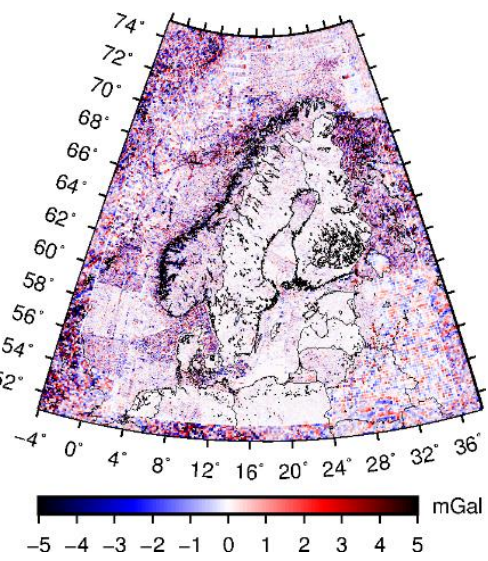

(c) $\mathrm{G} 7 \mathrm{C}-\Delta g^{R T M A, A, I}$ grid interpolated by LSC

(Norway $1 \mathrm{mGal}$ )

Figure 13. Reduced anomaly point values minus reduced grid values interpolated to point locations 


\section{ACCEPTED MANUSCRIPT}
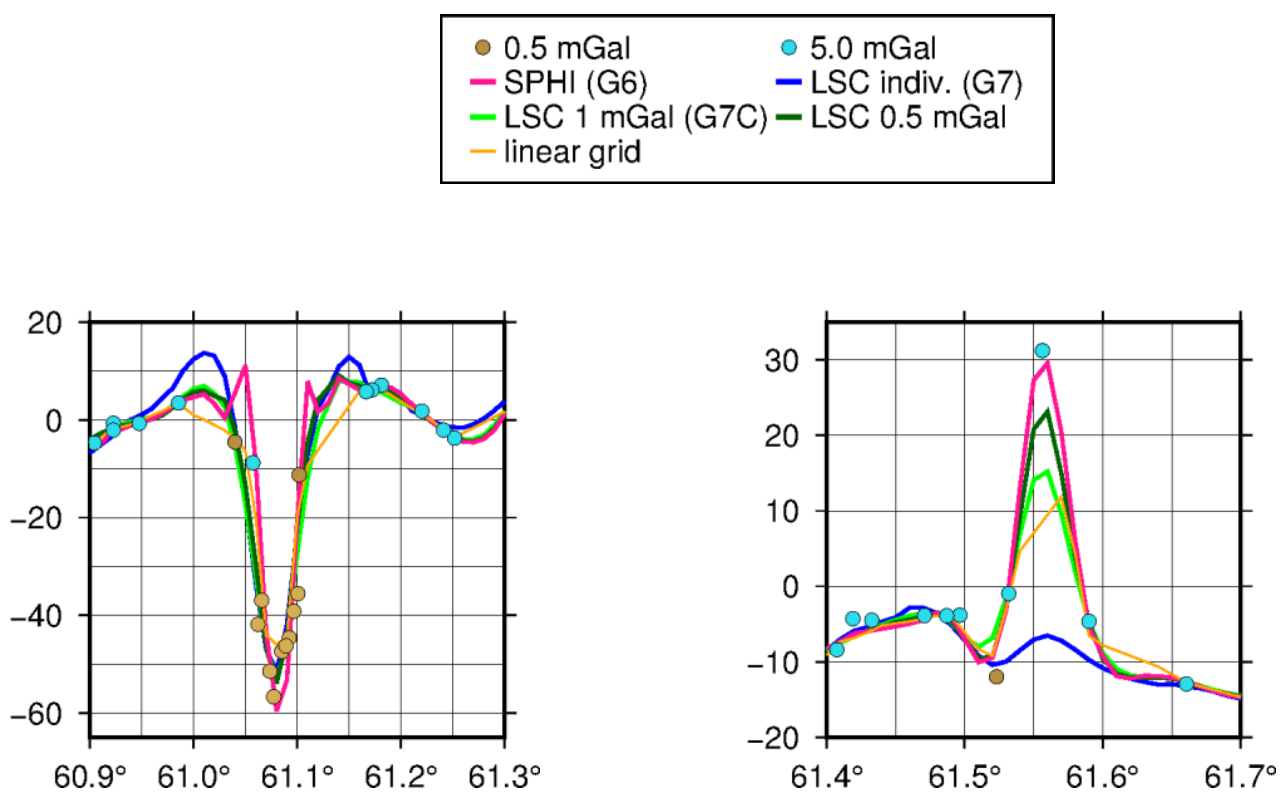
(a) $5.52^{\circ} \mathrm{E}$
(b) $7.72^{\circ} \mathrm{E}$

Figure 14. Profiles of free-air anomaly grids computed via RTM anomalies*

*The dots indicate input gravity data points coloured according to their a priori error estimates.

RTM anomalies in mGal and latitude are depicted on the vertical and horizontal axis respectively. 


\section{ACCEPTED MANUSCRIPT}
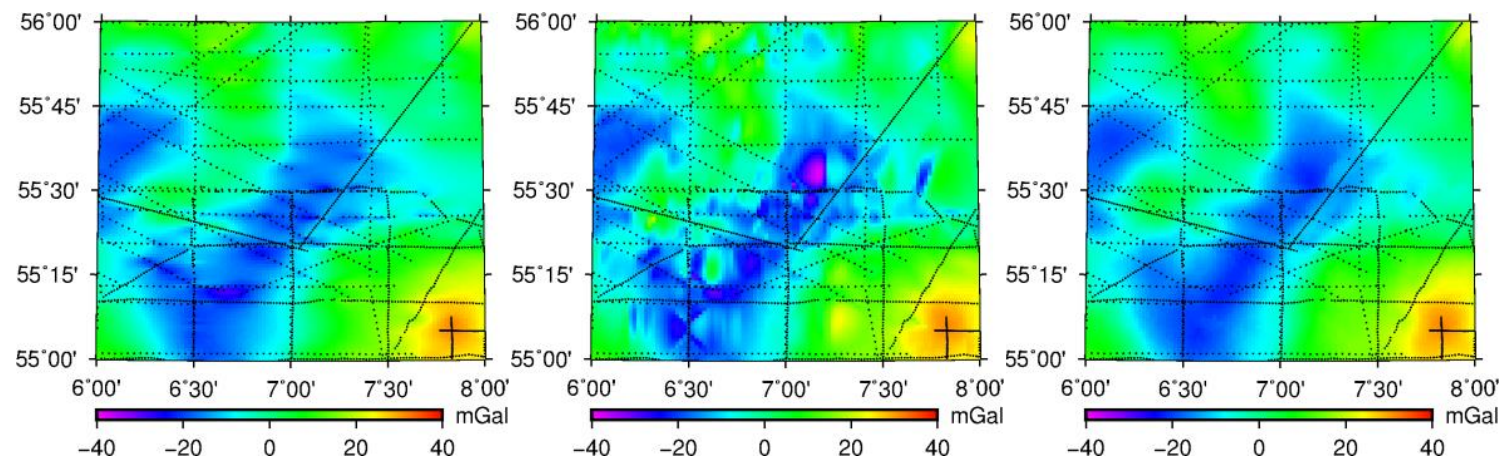
(a) G5 $-\Delta g^{R T M A, A, I}$ by
(b) G6 $-\Delta g^{R T M A, A, I}$ by SPHI (c) G7 $-\Delta g^{R T M A, A, I}$ by LSC
SURF

Figure 15. RTM anomaly grids in Area 3, black dots indicate the locations of input gravity data 


\section{ACCEPTED MANUSCRIPT}

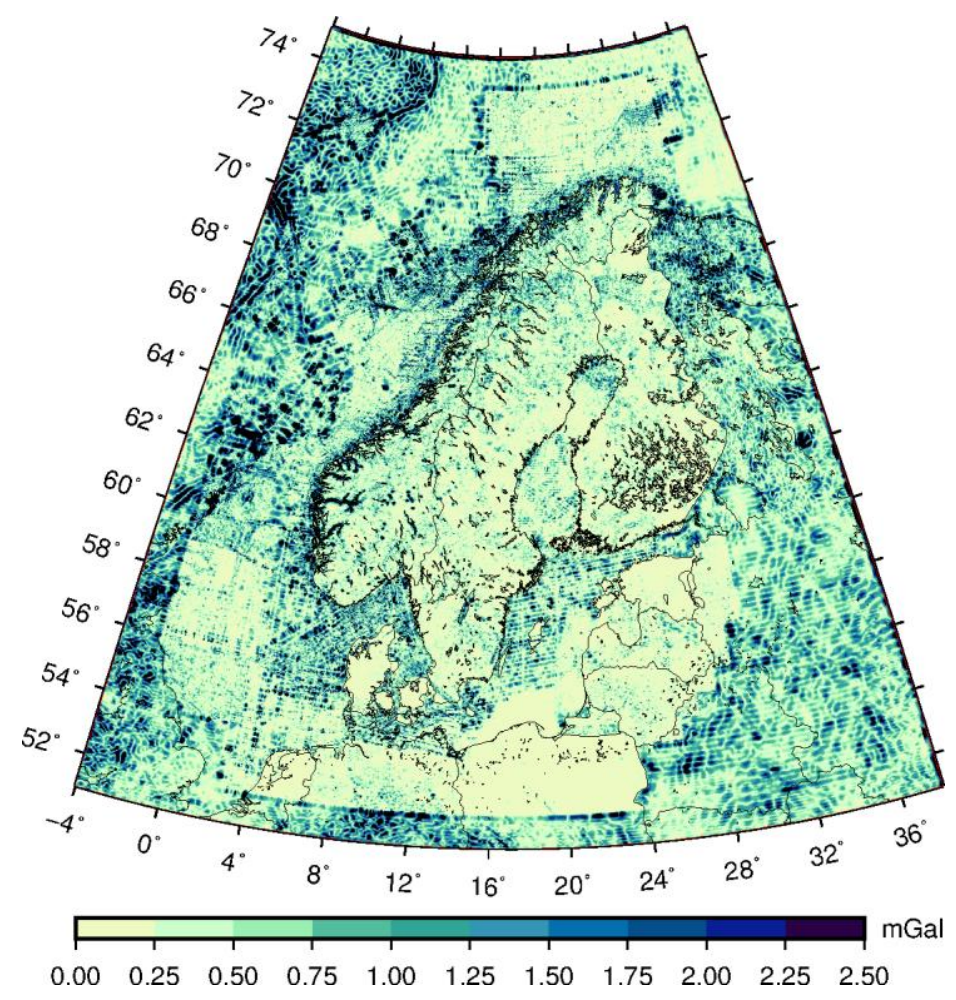

Figure 16. Standard deviation of G1 to G8 (with C versions of G3 and G7) surface gravity anomaly values in each grid cell 


\section{ACCEPTED MANUSCRIPT}

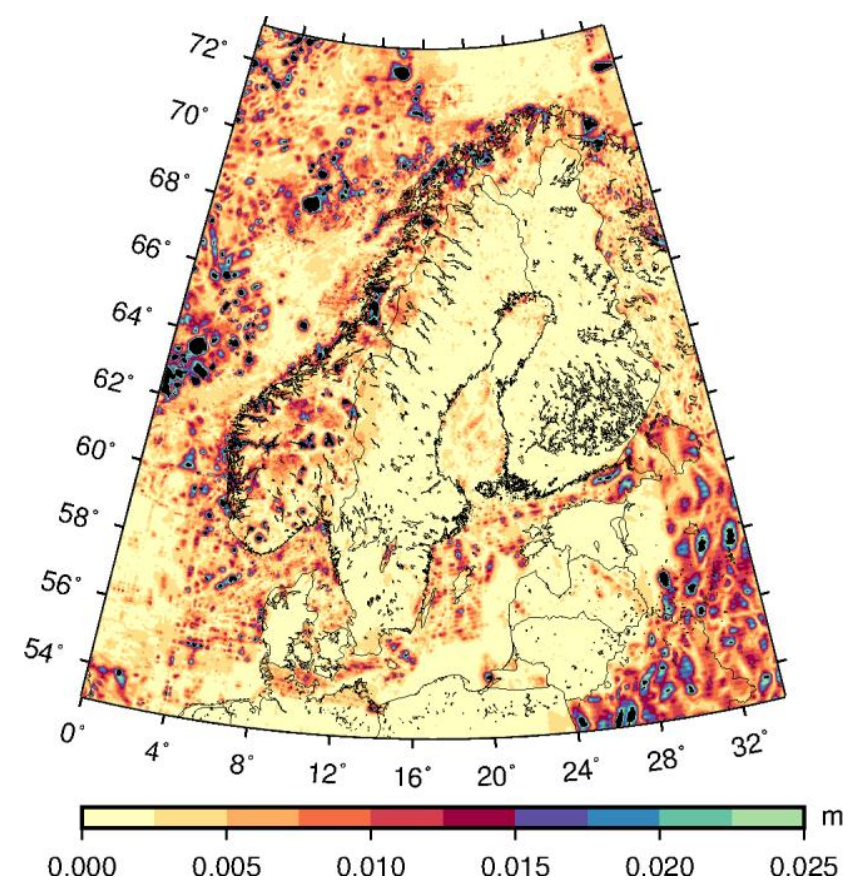

Figure 17. Standard deviation of quasigeoid models computed from G1 to G8 (with C versions of G3 and G7) in each grid cell 